\title{
Assessed and Emerging Biomarkers in Stroke and Training-Mediated Stroke Recovery: State of the Art
}

\author{
Marialuisa Gandolfi, ${ }^{1,2}$ Nicola Smania, ${ }^{1,2}$ Antonio Vella, ${ }^{3}$ \\ Alessandro Picelli, ${ }^{1,2}$ and Salvatore Chirumbolo ${ }^{1}$ \\ ${ }^{1}$ Department of Neurosciences, Biomedicine and Movement Sciences, University of Verona, Verona, Italy \\ ${ }^{2}$ UOC Neurorehabilitation, AOUI Verona, Verona, Italy \\ ${ }^{3}$ Immunology Unit, Azienda Ospedaliera Universitaria Integrata, Verona, Italy
}

Correspondence should be addressed to Marialuisa Gandolfi; marialuisa.gandolfi@univr.it

Received 9 November 2016; Accepted 11 January 2017; Published 8 March 2017

Academic Editor: Annalena Venneri

Copyright (C) 2017 Marialuisa Gandolfi et al. This is an open access article distributed under the Creative Commons Attribution License, which permits unrestricted use, distribution, and reproduction in any medium, provided the original work is properly cited.

\begin{abstract}
Since the increasing update of the biomolecular scientific literature, biomarkers in stroke have reached an outstanding and remarkable revision in the very recent years. Besides the diagnostic and prognostic role of some inflammatory markers, many further molecules and biological factors have been added to the list, including tissue derived cytokines, growth factor-like molecules, hormones, and microRNAs. The literatures on brain derived growth factor and other neuroimmune mediators, bone-skeletal muscle biomarkers, cellular and immunity biomarkers, and the role of microRNAs in stroke recovery were reviewed. To date, biomarkers represent a possible challenge in the diagnostic and prognostic evaluation of stroke onset, pathogenesis, and recovery. Many molecules are still under investigation and may become promising and encouraging biomarkers. Experimental and clinical research should increase this list and promote new discoveries in this field, to improve stroke diagnosis and treatment.
\end{abstract}

\section{Introduction}

Biomarkers in stroke have reached an outstanding and remarkable revision in the very recent years, since the increasing update of the biomolecular scientific literature in the field. Besides the diagnostic and prognostic role of some inflammatory markers, such as CRP, IL-6, TNF- $\alpha$, or IL-1 $\beta$, many further molecules and biological factors in the serum or plasma compartment have been added to the list, including tissue derived cytokines (myokines, adipokines), growth factor-like molecules, hormones, and microRNAs [1]. The latter ones have become important markers in many neurodegenerative and neuroimmune disorders, such as multiple sclerosis, Alzheimer disease, or Parkinson disease [2-5]. Neuroinflammation represents the main mechanism underlying the onset and development of stroke and the peripheral level of soluble immune factors and immune cells should give insights either on the onset and pathogenesis of stroke or on its recovery [6-8]. Poststroke rehabilitation, particularly following physical exercise and training, generates a crowded mass of mediators, more than 90, called myokines, which plays an emerging role in the biomarker field, which should update the role of plasma or circulating markers in stroke $[9,10]$ (see Figure 1).

Stroke risk and even poststroke recovery are strictly related to endothelial function. A correlation exists between arterial stiffness index and endothelia function in patients with acute ischemic stroke [11], while the association of stroke with hypertension should be better outlined. A recent paper reported that prestroke use of beta-blockers in hypertensive subjects did not affect neither stroke severity nor functional outcome [12]. The relationship between stroke and the cardiovascular system is particularly complex, as a huge panoply of different humoral and cellular participants make it highly complex to comprehend how stroke occurs and how to manage its recovery. Some recent papers revealed that the shortterm management of hypertension in hypertensive patients has a positive effect on the long-term risk reduction of stroke [13]. Elevated arterial pressure remains a fundamental risk 


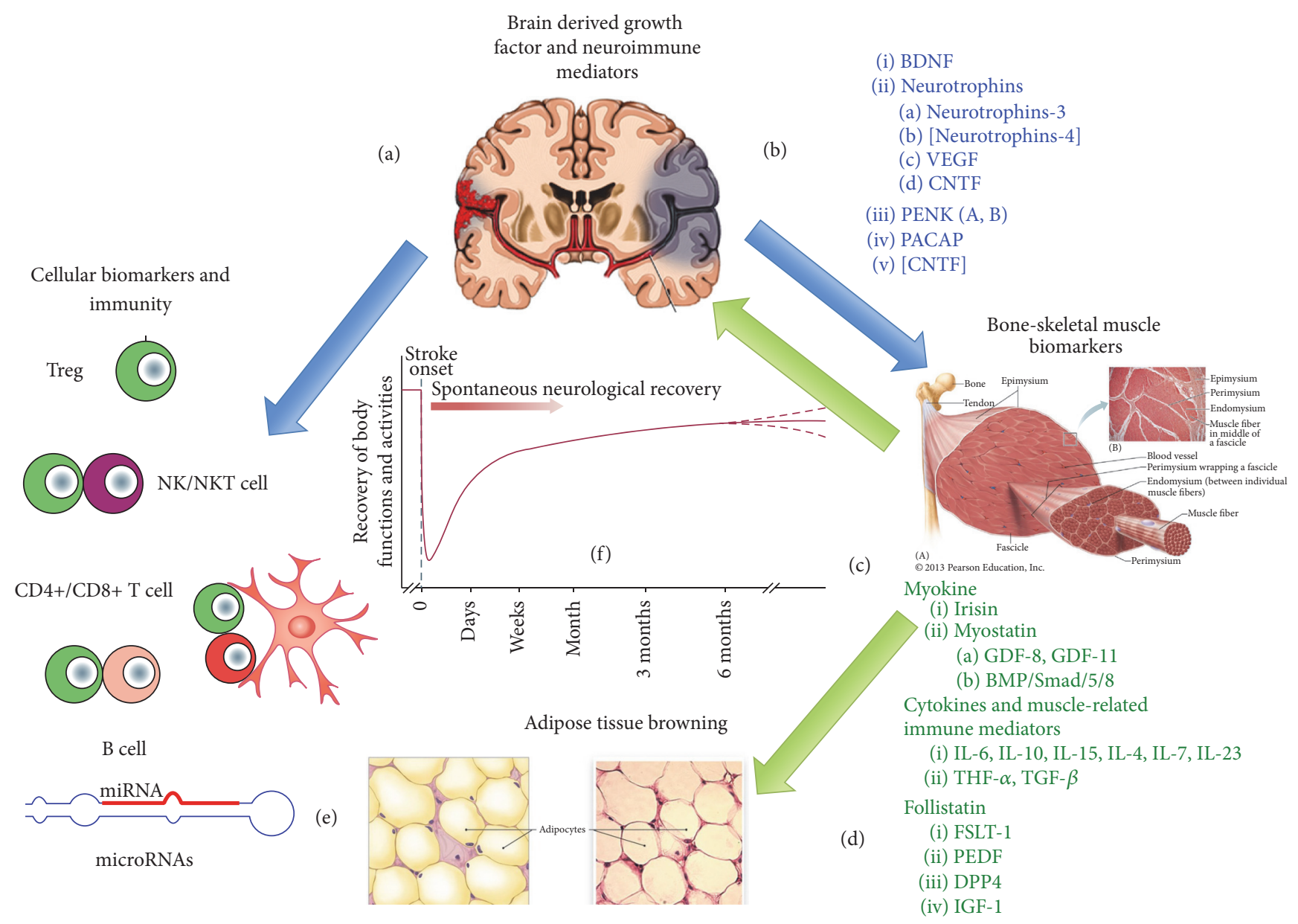

FIGURE 1: Cartoon showing the relationship between brain, muscle, and the immune system during stroke onset and stroke recovery, in order to highlight possible biomarkers of these events, as described in the text. Damaged brain, either following ischemic or hemorrhagic stroke, produces a panoply of different biomolecules, mainly BDNF or other neuromodulators, which link brain function with the immune system (a) and skeletal muscle (b). The first releases cytokines and cellular markers and the second one myokines, many of which interact with BDNF (c). Many of these myokines modulate the activity of other tissues such as vascular tissue (endothelia), bone, and adipose tissue. Irisin is a known "browning stimulator" (d). Downstream regulators of these mechanisms are represented by newly discovered miRNAs (e). The relationship between the activity of a defined biomarker (dose/time in plasma) and stroke recovery can be plotted in a time course curve as exemplified in (f).

factor also for the pediatric population, in elderly subjects [14]. This would mean that a major concern for rehabilitation medicine and neurology is the search for the best circulating markers of this relationship. Many of these markers, actually, pertain to the ability of the immune system to counteract with the oxidative and mechanical stress associated with the cardiovascular function.

The most recent literature on the field stresses on the role of inflammatory molecules as biomarkers in stroke. Stroke, which can be simply considered as an injury occurring in brain when blood flow is cut off, may be of ischemic or hemorrhagic nature and each year about 800,000 people experience a new or recurrent stroke, being the fifth leading cause of death in the United States and about a third in Italy [15-18]. This circumstance suggests that searching for new emerging biomarkers for either stroke predictivity, diagnosis, or prognosis has come in the spotlight and is asking for new insights and data from experimental research [19, 20]. Emerging new biomarkers should come from the many novelties in the scientific field of stroke, which should help clinicians to improve addressing this pathology and its dramatic consequences also on the social life and habits. This review tries to give a state of the art of the topic.

\section{Brain Derived Growth Factor (BDNF) and Other Neuroimmune Mediators in Stroke}

The involvement in stroke of BDNF, a $13 \mathrm{kDa}$ protein that belongs to the neurotrophin family, emerged some years ago. In particular low serum concentration of BDNF, particularly in the acute phase of ischemic stroke, is considered a factor of poor prognosis for the functional status of patients [57]. Physical exercise should ameliorate this circumstance, even by increasing the hippocampal level of BDNF in the early 
stages of a stroke (cerebral embolism) [58]. The enhancement of BDNF seems to be related to improvements in stroke recovery, even in animal models $[59,60]$, which show how social interactions are fundamental in the poststroke recovery [61]. BDNF increase in the hippocampus may improve also poststroke depression following estrogen-based therapy [37], a role that is also reached by physical exercise and muscular training [62]. Therefore, BDNF may be a good candidate to follow stroke development, even in chronic poststroke subjects, where circulating BDNF is very low with respect to controls $[47,48]$. Besides BDNF further neurotrophins were recently involved in stroke and may fulfil the list of potential biomarkers.

Neurotrophin-3 has a major role in both traumatic and ischemic injury of the brain, such as in stroke. It is produced by neuroglia as an adaptation factor to hypoxic conditions and, together with proinflammatory cytokines such as IL-6 and TNF- $\alpha$, it participates in the brain response to ischemic injury [49]. In mouse models, an upregulation of the neurotrophic receptor p75 (NTR) in striatal neurons during an ischemic damage was reported [40]. Neurotrophins should act with biochemical factors the ability of which is to regulated endothelial and vascular function. Actually, vascular endothelial growth factor (VEGF) has been recently associated with BDNF as a biomarker in stroke [63, 64], though with some criticism [39]. In animal models, the neurotrophin ciliary neurotrophic factor (CNTF), which is endogenously upregulated in a stroke onset, mediates the neurogenesis and an anti-inflammatory process [41]. The correct neuronastrocyte interaction dampens CNTF release, which is upregulated by astrocytes therefore during a traumatic or ischemic damage to this integrin-mediated linkage [42]. To date there are no evidence reporting the role of plasmatic CNTF in stroke, though the circulating levels of this neurotrophin have gained much more importance in the study of patients with amyotrophic lateral sclerosis [43]. Still, in rat models, neurotrophin- 4 increases its serum levels after a stroke event and exhibits the same properties of BDNF, as it is likewise a ligand of trkB [65]. Neuropeptide biology is moreover very rich of suggestions in order to retrieve emerging biomarkers for stroke. Yet, genetics should be involved in these issues, as genetic polymorphism highly influences the analytical performance of whatever would be introduced as a biomarker, particularly for neuropeptides. For example, neuropeptide Y may be a good prognostic biomarker in subjects with certain gene promoter polymorphisms [45]. Proenkephalin (PENK), or proenkephalin A, as proenkephalin B is known as prodynorphin, is a neuropeptide of recent introduction in the biomarker list. Its plasma level may be used as an indicator of prognostic outcome of stroke, as elevated concentrations in the bloodstream correlate with exacerbation of the cerebral injury $[66,67]$. The neuropeptide pituitary adenylate-cyclase activation protein (PACAP) is involved, as many other factors here described, in the poststroke neurogenesis [68]. Also PACAP increase in plasma may be used as a prognostic marker of stroke, as an increase has been associated with severity of intracranial hemorrhage [69]. Neuromediators in stroke, detectable in the bloodstream and being considered as emerging biomarkers, should suggest that the ability to set a panoply of biomarkers for diagnosis and prognosis of stroke is a fundamental point at issue in the clinical research of this pathology.

\section{Bone-Skeletal Muscle Biomarkers in Stroke}

The involvement of the skeletal and muscular function, and its relationship, in stroke prevention and management, should be taken into account when addressing the issue of stroke biomarkers, as skeletal muscle undergoes deep changes in poststroke events [70]. Furthermore, myokines play a major role in the cross-talk bone-muscle [27, 71]. The role of skeletal muscle in stroke is of major interest. Markers of inflammation increase both systematically and locally in the skeletal muscle during stroke, while the anti-inflammatory feedback mechanism involves both myokines and the cholinergic anti-inflammatory pathway, which should be activated by physical exercise [9]. Myokines are muscle derived factors, with a role similar either to cytokines or growth factors, which modulate the complex relationship between skeletal muscle and other fundamental compartments, such as bone or adipose tissue, and whose upregulation is dependent on subject's physical exercise [21, 22, 27, 72]. Their activity in stroke should suggest a possible role as biomarkers of stroke pathogenesis and/or recovery [73].

3.1. Irisin. Irisin, otherwise known with its precursor name, that is, fibronectin type III domain-containing protein 5 (FNDC5), is a muscular trans-membrane protein, with a fibronectin type III-like ectodomain that can be cleaved giving the soluble molecule known as irisin [74]. This myokine fundamentally regulates the cross-talk skeletal muscle-adipose tissue [71]. Serum levels of irisin increase with training and physical exercise [75, 76]; therefore it may appear intriguing to ascertain if irisin may be involved as a possible and promising serum marker in poststroke training and stroke recovery or neuromuscular rehabilitation. To the best of our knowledge, there are no or very few reports showing or suggesting a relationship between irisin and stroke. During heart failure (HF), the expression FNDC5 was related to an improvement in the aerobic performance in HF patients, therefore suggesting that FNDC5 may work as a hormone counteracting stress coming from injury, tissue damage, hypoxia, and inflammation [77]. Its association with training is yet much more encouraging. Together with other myokines and neuromodulators, irisin should participate in the regulation of resistance training periodization, particularly in subjects with sedentary or rarely active life [78]. Furthermore, physical exercise induces the hippocampal expression of the brain derived neurotropic factor (BDNF), through a PGC- $1 \alpha /$ FNDC5 pathway, that is, PGC- $1 \alpha$ (which is a marker of mitochondrial function and biogenesis), during endurance exercise in mice, which elicits the expression of the neuronal gene for FNDC5, which in turn induces BDNF expression [79]. This relationship irisin precursor, namely, FNDC5, and BDNF may be of fundamental importance in the comprehension of the role of training in stroke [80], particularly because physical exercise induces BDNF but also synapsin I in the hippocampal trisynaptic circuit [81]. BDNF 
induces local synaptic plasticity [82] and more interestingly cyclin-dependent kinase 5 (Cdk5), a serine/threonine kinase involved in the rescue of synaptic plasticity [83], is involved in the BDNF-stimulated dendritic growth in hippocampus [84]. In poststroke patients, the role of Cdk5 has been associated with the long-term postischemic neurodegeneration and Cdk5 might be a pharmacological target; its inhibition or gene silencing increases the expression of BDNF in the hippocampal neurons [85]. The loss of this serine/threonine kinase in the nucleus accumbens reduces the ability to sustain a muscular physical exercise [85]. The relationship between the different degrees of the muscular activity (training, sustained and endurance physical exercise, moderate aerobic exercise, etc.) and the newly incoming biomarkers is still puzzling, particularly if related to poststroke rehabilitation. The role of irisin and its precursor FNDC5 in stroke recovery with training is quite far to be fully elucidated. As far as irisin is concerned, both muscle and brain express this hormone, which even participates in neurological and neuropsychiatric function such as regulation of behaviour and the mechanism of boosting reward-related learning and motivation [86] and is considered as one of the major linkers between muscular activity and brain [23]. Both irisin and BDNF are possible candidates as markers of sarcopenia [24], together with the transforming growth factor- $\beta$ (TGF- $\beta$ ), follistatin, insulin-like growth factor-I (IGF-1), fibroblast growth factor2 (FGF-2), osteoglycin, FAM5C, interleukin (IL-6), leukemia inhibitory factor (LIF), IL-7, IL-15, monocyte chemoattractant protein-1 (MCP-1), ciliary neurotrophic factor (CNTF), osteonectin, and matrix metalloproteinase 2 (MMP2), which affect also bone cells [27]. It is tempting to speculate that serum irisin would be an emerging biomarker in the relationship muscular activity/brain function and possibly an emerging biomarker also for stroke recovery.

3.2. Myostatin. This myokine, known also as growth differentiation factor 8 (GDF-8), is a member of the TGF- $\beta$ protein family $[25,27]$ and has been recently related to the role and activity of GDF-11, with which it shares some similarities [25]. Myostatin is associated with muscle catabolism and actually antibodies against myostatin were considered to prevent sarcopenia, cancer cachexia, and muscle wasting disorders $[26,87]$. People who survive stroke experience a disproportionate atrophy of their muscle mass or other detrimental tissue changes in the composition on the paretic side. Recent evidence supports the suggestion for a fundamental role of myostatin in these subjects, as an increase in myostatin mRNA was reported in the paretic thigh, while a reduction was observed following resistive training [88]. The serum level of myostatin, which is a negative regulator of muscle growth, has been associated with muscle function in a maintenance grip strength; that is, higher serum myostatin has been related to lower muscle function [89] and is a marker of muscle wasting [90]. Myostatin shares with irisin or FNDC5 a role in the browning phenomenon of the adipose tissue; therefore this myokine, as well as irisin, has a role in glucose and fat metabolism, besides muscle function [91]. This would suggest a possible relationship between stroke and nutrition in the myokine activity $[92,93]$. Serum myostatin, as a possible biomarker in stroke-related disorders, has been reported for myocardial ischemia-related injury, as a cardiac myostatin upregulation immediately occurs after myocardial ischemia and participates in the ubiquitin-proteasome degradation of proteins, via the atrogin and MuRF1 involvement, in the skeletal muscle [94]. To the best of our knowledge, there are very few reports about the association of myostatin with poststroke neurorehabilitation, but evidence should suggest that this myokine may be upregulated following stroke and downregulated with muscular training. Animal models support this hypothesis. Muscle is involved in maintaining the bone mineral content and in electrical muscle stimulation following sciatic neurectomy in rats; muscle fibers downregulated myostatin gene expression, a model that should suggest the downregulation of this myokine in stroke-derived paretic limbs [95]. Cerebral ischemia causes also the activation of the bone morphogenetic protein (BMP)/Smad/5/8 signaling in muscle atrophy occurring following stroke. The ubiquitinproteasome degradation of muscle proteins in paretic limbs following the severe sensorimotor deficits after cerebral ischemia involves a biomolecular mechanism in muscle fibers that inhibits the Akt/mTOR pathway and increases, besides myostatin, many actors of the ubiquitin-proteasome degradation such as muscle RING finger-1 or MuRF1, muscle atrophy F-box (MAFbx), and muscle ubiquitin ligase of SCF complex in atrophy-1 or Musal [96]. This evidence may suggest even a role of myostatin as a prognostic marker for stroke.

3.3. Cytokines and Muscle-Related Immune Mediators. Skeletal muscle is one of the major producers of interleukin-6 (IL6), which contributes with other factors such as irisin to the fine regulation of bone metabolism and adipose tissue homeostasis after physical exercise $[10,97,98]$. The relationship between IL-6 and stroke is established principally by neuroinflammatory mechanisms in the CNS, where the expression of genes such as IL-6, besides myeloperoxidase (MPO), IL$1 \beta$, and TNF- $\alpha$, is fundamental for stroke susceptibility [99] but also myocardial stroke generates a peripheral proinflammatory response in skeletal muscle [100]. In chronic heart failure training muscular exercise reduces muscle production of IL-6, TNF- $\alpha$, IL-1 $\beta$, and iNOS [101] although those markers involved in muscle atrophy, that is, atrogin and MuRF1, do not change their expression pattern in skeletal muscle [102], assessing that this model is not fully comparable to stroke-related muscle disorders. Following stroke huge panoply of proinflammatory cytokines that are released in the bloodstream and detectable in the serum, besides IL6 and TNF- $\alpha$, also IL-10, IL-4, IL-17, IL-23, and TGF- $\beta$ increase [103]. Low frequency electrical stimulation together with acupuncture in denervation muscle induced atrophy in mice, reduced the expression of myostatin, and transiently increased the level of inflammation by enhancing the expression of IL-5, TNF- $\alpha$, arginase-1 expressing macrophages (M1type), and muscle specific microRNA, that is, miRNA-1 and miRNA-206, but also upregulated IGF-1 expression $[104,105]$. This should suggest that inflammation in muscle is initially triggered to attenuate muscle degeneration and atrophy, by activating, for example, mitochondria-biogenesis markers, 
such as PGC-1 $\alpha$ and autophagy [106-108]. Factors inhibiting autophagy in muscle fibers and the intracellular accretion of unfolded, damaged proteins may lead to apoptosis and muscle atrophy [109]. The intriguing relationship between muscle inflammation and PGC- $1 \alpha$ is finely modulated. At least, as emerging from in vitro heart models, PGC- $1 \alpha$ is upregulated following short-term exercise and interestingly an anti-inflammatory stimulus may reduce the activity of PGC- $1 \alpha$ by attenuating its downstream effectors, such as NRF-1 and several respiratory genes, as most probably oxidative stress generated by either inflammation or muscular exercise is a main trigger of PGC- $1 \alpha$ [110]. Mediators of this muscle response include several immune mediators besides IL-6. Interleukin 15 (IL-15) induces mitochondrial activity, via a PPAR- $\delta$ signaling during physical exercise [111]. Although there seems to be lack of evidence reporting a role of IL-15 in muscle atrophy following stroke, the most recent reports about this cytokine in this field suggest a possible involvement in this mechanism. At least, in diabetic rats, resistance training increasing both muscle and serum levels of IL-15 [112] and IL-15 is one of the main protective factors in sepsis-induced muscular wasting and proteolysis in mice [113]. In this sense, IL-15 should play a protective role against stroke or its dependent effects, as likely as further cytokines such as IL-19 [114] or IL-33 [115]. Despite its well-known anti-inflammatory role, IL-10 has been recently associated with worsening of muscle atrophy. Even a short bed rest in aged patients with leg lean mass or muscle wasting associated symptoms increases some proinflammatory cytokines and also IL-10 [116]. Furthermore, an excessive IL-10 response may even worsen stroke recovery, depending on genetics and sex $[117,118]$. Actually, the inflammatory participation in stroke recovery should be profoundly revised. Interleukin 6 is still associated with worsening in muscle activity $[119,120]$, assessing the detrimental role of inflammatory cytokines in stroke-dependent muscle damage. But, as an example, antiinflammatory drugs should act as a double-edged sword, both exacerbating brain injury and helping the pathway to poststroke recovery, suggesting the existence of more complex machinery in the neuromuscular rehabilitation [121]. For example, interleukin 17A (IL-17A), produced by $\gamma \delta \mathrm{T}$, cells was initially thought to have detrimental action in the pathogenesis of acute ischemic stroke but a deeper focusing onto its activity showed that IL-17A participates in neuronal differentiation, synaptogenesis, and spontaneous recovery following ischemic stroke [122]. Both IL-17A and IL-23 failed in being associated with biomarkers in muscle damage, following physical exercise [123]. Fundamentally, muscle produces cytokines that are widely expressed in the innate and adaptive immune system, such as IL-6, IL-8, IL10, IL-1ra, TNF- $\alpha$, MCP-1, IL-1 $\beta$, IL-12p35/p40, and IL-15 [124]. Particularly for IL-1 receptor antagonist (IL-1ra) it is well-known that this cytokine reverses immune suppression associated with stroke, generating concerns about the effect of immunosuppression during the acute phase of stroke [28]. Yet, there are controversial opinions about the therapeutic effect of this anti-inflammatory cytokine in stroke [29, 30]; probably one must distinguish the effect of systemic IL-1ra from local (e.g., skeletal muscle, myocardium). However, a lot of molecules with a growth factor-like activity have come in the spotlight as potential biomarkers in stroke.

\subsection{Follistatin-Like 1, Insulin Growth Factors, and Other} Myokines. Follistatin, known also as activin-binding protein $(\mathrm{ABP})$, is considered as an antagonist of myostatin. Recent reports showed that the ratio myostatin to follistatin is a good marker of the denervated muscular atrophy and its recovery [125]. Circulating follistatin levels are correlated with muscular mass in healthy individuals [126]; therefore its presence in the peripheral blood should be interpreted as a positive prognostic marker of the recovery of muscle damage and atrophy following stroke, a hallmark of several myokines $[73,127,128]$. Follistatin-like 1 is a myokine which promotes revascularization and endothelial cell function following an ischemic injury [129]. Follistatin-like 1 (FSTL1) is a protein very similar to follistatin, which does not bind to activin $A$, but rather BMP 4 and TGF- $\beta[130,131]$. The neuroprotective role of FSTL1 has been reported in rats, where the glycoprotein is able to repair and improve neuron deficits inducing Akt phosphorylation and hence its receptor disco-interacting protein 2 homolog A (DIP2A) activation [132, 133]. FSTL1 is a marker of remodelling also in cardiac function, where in subjects with heart failure an increase in the serum FSTL1 was observed [31]. Actually, FSTL1 has been recently considered an independent circulating biomarker of inflammation and oxidative stress and likewise hsCRP, associated with markers predictive of stroke [32]. Despite its proinflammatory-like nature [130], FSTL1 is a cardioprotective molecule, which is upregulated following exercise training, particularly after myocardial infarction [134] and which modulates vascular remodelling [33].

Serum level of FSTL1 may give fundamental insights on the individual's response to ischemic stress. Pigment epithelium derived factor (PEDF) known as serpin F1, is a myokine with neurotropic activity, which has been recently associated, as a neuroprotective and antiangiogenic agent in animal models, with ischemic stroke [34, 135]. However, to the best of our knowledge, there are yet no data about the association between serum PEDF and stroke-related disorders, particularly for muscle. Rat models showed that PEDF induces the production of inflammatory chemokines such as MIP-2 and MIP-3 $\alpha$ in microglia [136]. The myokine dipeptidyl-peptidase 4 (DPP4) has recently come in the spotlight because its inhibition, as well as the use of glucagonlike receptor 1 (GLP-1) agonists, leads to an antistroke effect $[137,138]$ and a cardioprotective role [139]. During physical exercise, DPP4 inhibitors improve mitochondrial biogenesis and muscle activity through the activation of GLP-1 signaling [140]. Yet, this myokine should act at a more systemic level, in the energetic balance of the organism, as their inhibitors are able to act in a similar way to sulfonylureas or pioglitazone for diabetes [141]. Insulin-like growth factors (IGFs), particularly with the involvement of CXCR4, are fundamental molecules in remodelling, even after stroke [50, 142, 143]. The serum level of IGF-1 in elderly men with muscle frailty has been considered as positive prognostic marker, also for bone mineral density [51]. IGF-I and IGF-II are important myokines recently related to stroke [52]. The relationship between IGF-1 
and physical training is particularly intriguing, as serum total IGF-1 in response to a resistance exercise is highly variable and depends on the subject's body mass [144]. However, recent reports indicate that IGF-1 has a major role, together with BDNF, in neuroplasticity and in the recovery of the neuromuscular function following stroke by active muscle exercise [145-147], although an excess in IGF-1 production can induce neuroinflammation and exacerbation of stroke effects, as occurring following treatment with apolipoprotein A-1 mimetic peptide, which reduces white matter damage from stroke [148]. Therefore, besides the complexity of events related to IGF-1 activity, even when associated with BDNF, for many emerging myokines a possible role as biomarkers in stroke yet needs confirmation in clinical studies, despite the encouraging evidence coming from in vitro or animal studies. Usually, the serum level of IGF-1 in patients with stroke-derived intracerebral hemorrhage during admission (hospitalization) is lower than healthy controls, while VEGF and hepatocyte growth factor (HGF) are higher [149]. Further factors related to IGFs have been recently associated with stroke and may suggest emerging biomarkers in this pathology. A recent study showed that not only low levels of IGF-1 were associated with an unfavourable functional outcome of stroke but also the level of insulin-like growth factor binding protein-3 (IGFBP-3) [35]. More favourable outcomes should be yet associated with the evaluation of the decrease in the IGF-1 ratio and with IGFBP-3, rather than with serum levels of IGF-1 [150]. Actually, a more complex relationship between IGF-1, IGF-II, IGFBP-1, and IGFBP3 should give important insights on the risk of ischemic stroke [151,152]. This complex pattern is a hallmark of many myokines involved in stroke. Myokines includes cytokines, hormone-like molecules, and growth factors. Fibroblast growth factor 21 (FGF21) is a myokine, which may be important in detecting subclinical atherosclerosis, which may be a pathogenetic cause of stroke [153]. FGF21 is related to metabolism, stress response, mitochondria function, and insulin resistance, as serum levels of FGF21 are elevated in certain types of mitochondria dysfunction, particularly in the muscle $[154,155]$. Some reports have investigated also its relationship with bone physiology but the topic asks for further insights [156, 157]. It would be interesting to ascertain if serum level of FGF21 may be associated with positive outcome given by physical exercise. This has been reported for metabolic syndrome [158], yet not for poststroke training; then FGF21 may be suggested as an indirect biomarker.

Table 1 summarizes most of the assessed and emerging biomarkers in stroke onset and recovery.

\section{Cellular Biomarkers and Immunity of Stroke}

The role of the immune system in stroke and in its recovery-rehabilitation process, using physical training or others, includes both soluble factors (cytokines, chemokines, myokines, adipokines, and neuroimmunokines) and immune cells. Immune cells may be investigated mainly using flow cytometry and can give fundamental insights on the role and activity of innate immunity in the remodelling process following stroke [55, 56, 103, 159-161]. Some circulating cytokines and reactive molecules, such as interleukin 11 (IL11), are considered important markers of ischemic stroke $[162,163]$, though some consideration should be taken into account about the role of the different subtypes of stroke [164]. Cellular signals, such as the immunoproteasome, are correlated with ischemic stroke with intracranial hemorrhage [165]. The phenotypic subsetting of the different lymphocyte populations would be an interesting biomarker of stroke and stroke recovery. For example, a peripheral persistence of $\mathrm{CD} 4^{+} \mathrm{CD} 28^{-} \mathrm{T}$ cells (CD28 null cells) has been reported in acute ischemic stroke [166], assessing previously reported evidence [167]. Fox $\mathrm{P}^{+} \mathrm{CD} 25^{+} \mathrm{CD} 4^{+}$regulatory T cells (Tregs) are presumably involved in stroke-related events [168]. In this regard, the program death 1 ligand (PF-L1) on Tregs should have a major role in neuroprotection against cerebral ischemia, as it mediated the suppressive action exerted by Tregs on metalloproteinase 9 (MMP9), which is released by inflamed neutrophils [169]. Innate immunity plays a fundamental role in stroke. It has been recently reported that nucleotide binding oligomerization domain- (NOD-) like receptors (NLRs), which are a class of cytoplasmic patternrecognition receptors, are upregulated and highly expressed in a mouse model of ischemic stroke [170]. Recent pharmacological strategies have taken into consideration the innate immune hallmark of inflammation in stroke. This allowed researchers to realize that the anti-inflammatory mechanism induced by the damaged brain may be a good target for therapy. The cholinergic anti-inflammatory pathway, when modulated by $\alpha 7$-nicotinic acetylcholine receptor ( $\alpha 7$-nAChR) ligands, may facilitate stroke recovery. By using a polychromatic flow cytometry approach, it is possible to investigate how circulating leukocytes change their surface phenotypes and subtypes and/or their amount in relation to strokeassociated-events. Invariant natural killer $\mathrm{T}$ cells (iNKT) infiltrate mouse ischemic hemisphere in animals undergoing an ischemic stroke [171, 172]. Alpha-galactosyl ceramide $(\alpha \mathrm{GC})$, which specifically activates iNKT, is requested to promote the protective role of iNKT in myocardial stroke [173], a circumstance that would be suggested also for brain stroke [172]. A high number of circulating NK cells within the first hours of an ischemic stroke, particularly if followed by a rapid falling down of other lymphocyte subsets, may indicate a possible risk of pejorative inflammatory disorders in stroke patients [174]. Infiltrations of NK cells in brain occur also in human during ischemic stroke, where cells are probably activated by IP-10 [175]. This evidence assesses the role of innate immune cells infiltration in the development of stroke-related damage. Stroke-induced lymphopenia is related to a reduction of circulating high mobility group protein B1 (HMGPB1) and by the activity of T cells [176]. $\mathrm{CD}^{+} \mathrm{T}$ cells, together with $\mathrm{CD} 8^{+}, \gamma \delta$-T cells, and Tregs, change their peripheral pattern following stroke [177]. Very recently, Klehmet et al. reported that stroke induces defined alterations in the memory T cell compartment [178]. Gammadelta $\mathrm{T}$ cells, which are with Th17 the main producers of IL-17A, increase dramatically during ischemic stroke [179]. Leukocyte subtypes that dynamically should change with 


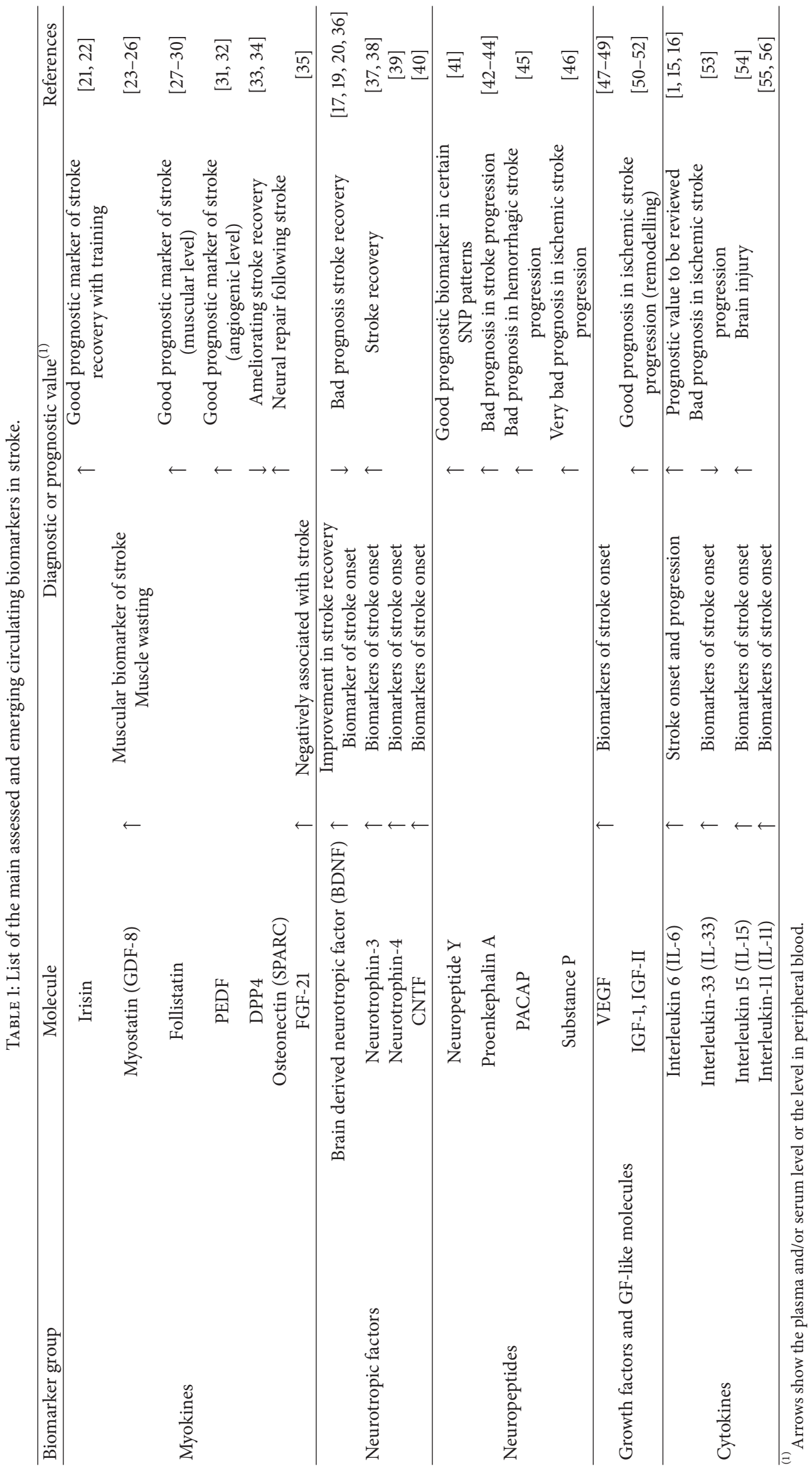


stroke and change their surface markers are very different depending on the time of stroke onset and its subtype. Therefore, this evidence should render particularly complex any interpretation of the flow cytometry panel used to highlight the percentage and nature of the various lymphocyte subsets in the bloodstream. B cell compartment is also involved in stroke biology. Particularly, for pre-B cells, the released factor nicotinamide phosphoribosyltransferase (NAMPT), more simply known as pre-B-cell colony-enhancing factor (PBEF), plays a fundamental role in the mitochondrial survival and biogenesis after ischemic damage, protecting neurons from apoptosis [180]. B cells in stroke showed heterogeneity in their function and subtypes and participate in prestroke neuroprotective mechanisms [181]. Regulatory B cells contribute to limiting the inflammatory events occurring in CNS following stroke and IL-10 secreting B cells appear to have the major role in this mechanism [182]. Regulatory $\mathrm{T}$ cells have also a fundamental function in addressing stroke-related damage, particularly in poststroke recovery [183]. Actually, their role in this recovery process has suggested Tregs as a cellular therapy in stroke [170].

Much lesser importance has been given to circulating granulocytes in their possible relationship with stroke. Peripheral eosinophils have been associated with stroke, as the eosinophil count appears to have a fundamental impact on the outcome of stroke [184]. Blood neutrophil counts appeared to be associated with intracranial hemorrhage following stroke but this association was recently criticized $[185,186]$. A role for basophils in stroke was reported several years ago but there is no further association to date, although mast cells are probably the early responders in the regulation, following ischemic stroke, of the blood-brain barrier $[187,188]$. At least in mouse models, the CD36+ monocyte/macrophage system is involved in the poststroke recovery phase, leading to a correct phagocytosis [189]. In these models, monocyte-derived macrophages exhibit a repair function in the poststroke event [190]. Very recently, the role of monocytes in ischemic stroke has been thoroughly reviewed [191]. Interestingly, monocytes recruited to the ischemic site in mouse differentiate to an alternative activated macrophage (AAM) or M2-macrophage [56].

Particular interest has been recently devoted to brain dendritic cells in stroke events [192]. However, also antigen-presenting cells (APCs) in peripheral blood should give important insight on immune response to stroke and the mechanism of tolerance [193]. During cerebral focal ischemia a reduced peripheral costimulatory activity has been observed [194]. Stroke generates imbalance in the acquired immune response and a decrease in circulating dendritic cells [195].

\section{MicroRNAs as Biomarkers in Stroke}

MicroRNAs are the latest novelty in the emerging role of biomarkers in stroke [196]. These short modulatory RNA fragments play a fundamental role in the management of stroke, as much as that polymorphism in the microRNAs miRNA-130b, miRNA-200b, and miRNA-495 affects stroke susceptibility and the level of poststroke outcome [197].
MicroRNAs participate in the regulation of blood-brain barrier and in the function of microglia and astrocytes [198, 199]. Peripheral microRNAs are promising and emergent biomarkers for stroke [200]. Some miRNAs play prognostic or high diagnostic value to evaluate or predict stroke onset and development.

For example, low level of serum miRNA-320b is a highrisk factor for carotid atherosclerosis, a prodromic event possibly leading to cerebral ischemia and stroke [201], while miRNA-146a correlates with neuroprotection from cerebral ischemia [202]. The downregulation of miRNA-30a reduces ischemic injury via the enhancement of the beclin-1 mediated autophagy [203]. This neuroprotection role is exerted also by the downregulation of miRNA-181b, at least in the mouse model, via the involvement of the heat shock protein 45 and the ubiquitin carboxyl-terminal hydrolase isozyme L1, a role shared also by miRNA-30a [204, 205]. A neuroprotective role is exerted by miRNA-134 by targeting another heat shock protein, namely, HSPA12B [36]. Mesenchymal stem cells (MSC) may be primed by serum from stroke patients and this priming upregulates the expression of miRNA-20a, which in turn promotes MSC proliferation by regulating cell cycle and p21 CDKN1A [38]. This should suggest that miRNA-20a participates in the remodelling of damaged tissue after stroke. MicroRNAs as a biomarker for stroke may use either cerebrospinal fluid (CSF) or peripheral blood. After stroke some miRNAs, such as let-7c an miRNA-221$3 p$, are upregulated in CSF, while, in whole blood, where more than 250 different miRNAs were detected, miRNA-15la$3 p$ and miRNA-140-5p were upregulated while miRA-18b-5p was downregulated [44, 46, 53, 54, 206-210].

\section{Conclusions}

Biomarkers in stroke represent a possible challenge in the diagnostic and prognostic evaluation of stroke onset and pathogenesis and in poststroke recovery. Many of the molecules described in the text are still under investigation and may become promising and encouraging biomarkers, either diagnostic or prognostic emerging biomarkers. In this perspective, research is actually asking for further insights, particularly about newly incoming myokines (for stroke recovery following muscular training) but also for those neuropeptidergic and neurotropic molecules, which should be better suited to fit as circulating biomarker in stroke rehabilitation due to nonmuscle exercise. Experimental and clinical research should increase this list and promote new discoveries in this field, in order to improve stroke diagnosis and treatment.

\section{Competing Interests}

The authors declare that they have no competing interests.

\section{Acknowledgments}

The authors acknowledge support from the James S. McDonnell Foundation 21st Century Science Initiative in Cognitive Rehabilitation-Collaborative Award (\#220020413). 


\section{References}

[1] Q. Ji, Y. Ji, J. Peng et al., "Increased brain-specific MiR-9 and MiR-124 in the serum exosomes of acute ischemic stroke patients," PLoS ONE, vol. 11, no. 9, Article ID e0163645, 2016.

[2] M. Kacperska, J. Walenczak, and B. Tomasik, "Plasmatic microRNA as potential biomarkers of multiple sclerosis: literature review," Advances in Clinical and Experimental Medicine, vol. 25, no. 4, pp. 775-779, 2016.

[3] P. H. Reddy, S. Tonk, S. Kumar et al., "A critical evaluation of neuroprotective and neurodegenerative MicroRNAs in Alzheimer's disease," Biochemical and Biophysical Research Communications, 2016.

[4] L. Qiu, E. K. I. Tan, and L. Zeng, "microRNAs and neurodegenerative diseases," Advances in Experimental Medicine and Biology, vol. 888, pp. 85-105, 2015.

[5] Y. Xie and Y. Chen, "microRNAs: emerging targets regulating oxidative stress in the models of Parkinson's disease," Frontiers in Neuroscience, vol. 10, article no. 298, 2016.

[6] N. Quillinan, P. S. Herson, and R. J. Traystman, "Neuropathophysiology of brain injury," Anesthesiology Clinics, vol. 34, no. 3, pp. 453-464, 2016.

[7] M. S. V. Elkind, "Inflammatory markers and stroke," Current Cardiology Reports, vol. 11, no. 1, pp. 12-20, 2009.

[8] R. B. Schnabel and S. Blankenberg, "Commentary: Circulating cytokines and risk stratification of stroke incidence-will we do better in future?" International Journal of Epidemiology, vol. 38, no. 1, pp. 261-262, 2009.

[9] H. J. Coelho Junior, B. B. Gambassi, T. A. Diniz et al., "Inflammatory mechanisms associated with skeletal muscle sequelae after stroke: role of physical exercise," Mediators of Inflammation, vol. 2016, Article ID 3957958, 19 pages, 2016.

[10] A. P. Lightfoot and R. G. Cooper, "The role of myokines in muscle health and disease," Current Opinion in Rheumatology, vol. 28, no. 6, pp. 661-666, 2016.

[11] A. Tuttolomondo, A. Casuccio, V. Della Corte et al., "Endothelial function and arterial stiffness indexes in subjects with acute ischemic stroke: relationship with TOAST subtype," Atherosclerosis, vol. 256, pp. 94-99, 2017.

[12] S. Koton, D. Tanne, and E. Grossman, "Prestroke treatment with beta-blockers for hypertension is not associated with severity and poor outcome in patients with ischemic stroke," Journal of Hypertension, 2016.

[13] Z. Wang, G. Hao, X. Wang et al., "Short-term hypertension management in community is associated with long-term risk of stroke and total death in China: a community controlled trial," Medicine, vol. 95, no. 48, p. e5245, 2016.

[14] J. C. Kupferman, D. I. Zafeiriou, M. B. Lande, F. J. Kirkham, and S. G. Pavlakis, "Stroke and hypertension in children and adolescents," Journal of Child Neurology, vol. 32, no. 4, pp. 408417, 2017.

[15] R. Chen, B. Ovbiagele, and W. Feng, "Diabetes and stroke: epidemiology, pathophysiology, pharmaceuticals and outcomes," The American Journal of the Medical Sciences, vol. 351, no. 4, pp. 380-386, 2016.

[16] S. Sacco, F. Stracci, D. Cerone, S. Ricci, and A. Carolei, "Epidemiology of stroke in Italy," International Journal of Stroke, vol. 6, no. 3, pp. 219-227, 2011.

[17] V. Arnao, M. Acciarresi, E. Cittadini, and V. Caso, "Stroke incidence, prevalence and mortality in women worldwide," International Journal of Stroke, vol. 11, no. 3, pp. 287-301, 2016.
[18] T. Truelsen, B. Piechowski-Jóźwiak, R. Bonita, C. Mathers, J. Bogousslavsky, and G. Boysen, "Stroke incidence and prevalence in Europe: a review of available data," European Journal of Neurology, vol. 13, no. 6, pp. 581-598, 2006.

[19] A. Shoamanesh, S. R. Preis, A. S. Beiser et al., "Circulating biomarkers and incident ischemic stroke in the Framingham Offspring Study," Neurology, vol. 87, no. 12, pp. 1206-1211, 2016.

[20] O. S. Mattila, H. Harve, S. Pihlasviita et al., "Ultra-acute diagnostics for stroke: large-scale implementation of prehospital biomarker sampling," Acta Neurologica Scandinavica, 2016.

[21] B. K. Pedersen, "Exercise-induced myokines and their role in chronic diseases," Brain, Behavior, and Immunity, vol. 25, no. 5, pp. 811-816, 2011.

[22] J. Dong, Y. Dong, Y. Dong, F. Chen, W. E. Mitch, and L. Zhang, "Inhibition of myostatin in mice improves insulin sensitivity via irisin-mediated cross talk between muscle and adipose tissues," International Journal of Obesity, vol. 40, no. 3, pp. 434-442, 2016.

[23] J. Zhang and W. Zhang, "Can irisin be a linker between physical activity and brain function?" Biomolecular Concepts, vol. 7, no. 4, pp. 253-258, 2016.

[24] A. Kalinkovich and G. Livshits, "Sarcopenia-the search for emerging biomarkers," Ageing Research Reviews, vol. 22, pp. 5871, 2015.

[25] R. G. Walker, T. Poggioli, L. Katsimpardi et al., "Biochemistry and biology of GDF11 and myostatin: similarities, differences, and questions for future investigation," Circulation Research, vol. 118, no. 7, pp. 1125-1142, 2016.

[26] M. R. Laurent, V. Dubois, F. Claessens et al., "Muscle-bone interactions: from experimental models to the clinic? A critical update," Molecular and Cellular Endocrinology, vol. 432, pp. 1436, 2016.

[27] H. Kaji, "Effects of myokines on bone," BoneKEy Reports, vol. 5, article 826, 2016.

[28] C. J. Smith, H. C. Emsley, C. T. Udeh et al., "Interleukin-1 receptor antagonist reverses stroke-associated peripheral immune suppression," Cytokine, vol. 58, no. 3, pp. 384-389, 2012.

[29] S. K. McCann, F. Cramond, M. R. Macleod, and E. S. Sena, "Systematic review and meta-analysis of the efficacy of interleukin1 receptor antagonist in animal models of stroke: an update," Translational Stroke Research, vol. 7, no. 5, pp. 395-406, 2016.

[30] V. Banwell, E. S. Sena, and M. R. Macleod, "Systematic review and stratified meta-analysis of the efficacy of interleukin-1 receptor antagonist in animal models of stroke," Journal of Stroke and Cerebrovascular Diseases, vol. 18, no. 4, pp. 269-276, 2009.

[31] A. El-Armouche, N. Ouchi, K. Tanaka et al., "Follistatin-like 1 in chronic systolic heart failure a marker of left ventricular remodeling," Circulation: Heart Failure, vol. 4, no. 5, pp. 621627, 2011.

[32] S. Hayakawa, K. Ohashi, R. Shibata et al., "Association of circulating follistatin-like 1 levels with inflammatory and oxidative stress markers in healthy men," PLoS ONE, vol. 11, no. 5, Article ID e0153619, 2016.

[33] M. Miyabe, K. Ohashi, R. Shibata et al., "Muscle-derived follistatin-like 1 functions to reduce neointimal formation after vascular injury," Cardiovascular Research, vol. 103, no. 1, pp. 111120, 2014.

[34] E. J. Duh, H. S. Yang, I. Suzuma et al., "Pigment epitheliumderived factor suppresses ischemia-induced retinal neovascularization and VEGF-induced migration and growth," Investigative Ophthalmology and Visual Science, vol. 43, no. 3, pp. 821829, 2002. 
[35] M. Ebinger, N. Ipsen, C. O. Leonards et al., "Circulating insulinlike growth factor binding protein-3 predicts one-year outcome after ischemic stroke," Experimental and Clinical Endocrinology and Diabetes, vol. 123, no. 8, pp. 461-465, 2015.

[36] W. Chi, F. Meng, Y. Li et al., "Downregulation of miRNA134 protects neural cells against ischemic injury in N2A cells and mouse brain with ischemic stroke by targeting HSPA12B," Neuroscience, vol. 277, pp. 111-122, 2014.

[37] Q. Su, Y. Cheng, K. Jin et al., "Estrogen therapy increases BDNF expression and improves post-stroke depression in ovariectomy-treated rats," Experimental and Therapeutic Medicine, vol. 12, no. 3, pp. 1843-1848, 2016.

[38] E. H. Kim, D. H. Kim, H. R. Kim, S. Y. Kim, H. H. Kim, and O. Y. Bang, "Stroke serum priming modulates characteristics of mesenchymal stromal cells by controlling the expression miRNA-20a," Cell Transplantation, vol. 25, no. 8, pp. 1489-1499, 2016.

[39] M. B. Jensen, M. R. Chacon, J. A. Sattin, A. Aleu, and P. D. Lyden, "The promise and potential pitfalls of serum biomarkers for ischemic stroke and transient ischemic attack," Neurologist, vol. 14, no. 4, pp. 243-246, 2008.

[40] G. Andsberg, Z. Kokaia, and O. Lindvall, "Upregulation of p75 neurotrophin receptor after stroke in mice does not contribute to differential vulnerability of striatal neurons," Experimental Neurology, vol. 169, no. 2, pp. 351-363, 2001.

[41] S. S. Kang, M. P. Keasey, S. A. Arnold, R. Reid, J. Geralds, and T. Hagg, "Endogenous CNTF mediates stroke-induced adult CNS neurogenesis in mice," Neurobiology of Disease, vol. 49, no. 1, pp. 68-78, 2013.

[42] S. S. Kang, M. P. Keasey, J. Cai, and T. Hagg, "Loss of neuronastroglial interaction rapidly induces protective CNTF expression after stroke in mice," Journal of Neuroscience, vol. 32, no. 27, pp. 9277-9287, 2012.

[43] H. Laaksovirta, S. Soinila, V. Hukkanen, M. Röyttä, and M. Soilu-Hänninen, "Serum level of CNTF is elevated in patients with amyotrophic lateral sclerosis and correlates with site of disease onset," European Journal of Neurology, vol. 15, no. 4, pp. 355-359, 2008.

[44] S. S. Sørensen, A.-B. Nygaard, M.-Y. Nielsen, K. Jensen, and T. Christensen, "miRNA expression profiles in cerebrospinal fluid and blood of patients with acute ischemic stroke," Translational Stroke Research, vol. 5, no. 6, pp. 711-718, 2014.

[45] X.-F. Fu, X. Zhang, D.-J. Wang, B. Zhao, and Y.-R. Li, "Neuropeptide Y gene promoter -399T/C polymorphism increases risk of ischemic stroke," Balkan Medical Journal, vol. 30, no. 2, pp. 147-150, 2013.

[46] C. Rink and S. Khanna, "MicroRNA in ischemic stroke etiology and pathology," Physiological Genomics, vol. 43, no. 10, pp. 521528, 2011.

[47] G. L. Santos, C. C. Alcântara, M. A. Silva-Couto, L. F. GarcíaSalazar, and T. L. Russo, "Decreased brain-derived neurotrophic factor serum concentrations in chronic post-stroke subjects," Journal of Stroke and Cerebrovascular Diseases, vol. 25, no. 12, pp. 2968-2974, 2016.

[48] A. Alhusban, A. Y. Fouda, and S. C. Fagan, "ARBs improve stroke outcome through an AT2-dependent, BDNF-induced proangiogenic and pro-recovery response," Neural Regeneration Research, vol. 11, no. 6, pp. 912-913, 2016.

[49] D. Pasarica, M. Gheorghiu, F. Topârceanu, C. Bleotu, L. Ichim, and T. Trandafir, "Neurotrophin-3, TNF-alpha and IL-6 relations in serum and cerebrospinal fluid of ischemic stroke patients," Roumanian Archives of Microbiology and Immunology, vol. 64, no. 1-4, pp. 27-33, 2005.

[50] J. Ren and P. Anversa, "The insulin-like growth factor I system: physiological and pathophysiological implication in cardiovascular diseases associated with metabolic syndrome," Biochemical Pharmacology, vol. 93, no. 4, pp. 409-417, 2015.

[51] M. I. Mohamad and M. S. Khater, "Evaluation of insulin like growth factor-1 (IGF-1) level and its impact on muscle and bone mineral density in frail elderly male," Archives of Gerontology and Geriatrics, vol. 60, no. 1, pp. 124-127, 2015.

[52] R. Kooijman, S. Sarre, Y. Michotte, and J. D. Keyser, "Insulinlike growth factor I: a potential neuroprotective compound for the treatment of acute ischemic stroke?" Stroke, vol. 40, no. 4, pp. e83-e88, 2009.

[53] M. Niimi, K. Hashimoto, W. Kakuda et al., "Role of brainderived neurotrophic factor in beneficial effects of repetitive transcranial magnetic stimulation for upper limb hemiparesis after stroke," PLoS ONE, vol. 11, no. 3, Article ID e0152241, 2016.

[54] X.-L. Chen, B.-J. Yu, and M.-H. Chen, "Circulating levels of neuropeptide proenkephalin A predict outcome in patients with aneurysmal subarachnoid hemorrhage," Peptides, vol. 56, pp. 111-115, 2014.

[55] C. Iadecola and J. Anrather, "The immunology of stroke: from mechanisms to translation," Nature Medicine, vol. 17, no. 7, pp. 796-808, 2011.

[56] F. Miró-Mur, X. Urra, M. Gallizioli, A. Chamorro, and A. M. Planas, "Antigen presentation after stroke," Neurotherapeutics, vol. 13, no. 4, pp. 719-728, 2016.

[57] A. Lasek-Bal, H. Jędrzejowska-Szypułka, J. Różycka et al., "Low concentration of BDNF in the acute phase of ischemic stroke as a factor in poor prognosis in terms of functional status of patients," Medical Science Monitor, vol. 21, pp. 3900-3905, 2015.

[58] N. Himi, H. Takahashi, N. Okabe et al., "Exercise in the early stage after stroke enhances hippocampal brain-derived neurotrophic factor expression and memory function recovery," Journal of Stroke and Cerebrovascular Diseases, vol. 25, no. 12, pp. 2987-2994, 2016.

[59] X. Li, W. Zheng, H. Bai et al., "Intravenous administration of adipose tissue-derived stem cells enhances nerve healing and promotes BDNF expression via the TrkB signaling in a rat stroke model," Neuropsychiatric Disease and Treatment, vol. 12, pp. 1287-1293, 2016.

[60] R. Verma, N. M. Harris, B. D. Friedler et al., "Reversal of the detrimental effects of post-stroke social isolation by pairhousing is mediated by activation of BDNF-MAPK/ERK in aged mice," Scientific Reports, vol. 6, Article ID 25176, 2016.

[61] V. R. Venna and L. D. McCullough, "Role of social factors on cell death, cerebral plasticity and recovery after stroke," Metabolic Brain Disease, vol. 30, no. 2, pp. 497-506, 2015.

[62] J. Lu, Y. Xu, W. Hu et al., "Exercise ameliorates depression-like behavior and increases hippocampal BDNF level in ovariectomized rats," Neuroscience Letters, vol. 573, pp. 13-18, 2014.

[63] A. Pikula, A. S. Beiser, T. C. Chen et al., "Serum brain-derived neurotrophic factor and vascular endothelial growth factor levels are associated with risk of stroke and vascular brain injury framingham study," Stroke, vol. 44, no. 10, pp. 2768-2775, 2013.

[64] A. Pikula, A. S. Beiser, C. Decarli et al., "Multiple biomarkers and risk of clinical and subclinical vascular brain injury: the framingham offspring study," Circulation, vol. 125, no. 17, pp. 2100-2107, 2012. 
[65] J.-Y. Chung, M.-W. Kim, M.-S. Bang, and M. Kim, "Increased expression of neurotrophin 4 following focal cerebral ischemia in adult rat brain with treadmill exercise," PLOS ONE, vol. 8, no. 3, Article ID e52461, 2013.

[66] W. Doehner, S. Von Haehling, J. Suhr et al., "Elevated plasma levels of neuropeptide proenkephalin a predict mortality and functional outcome in ischemic stroke," Journal of the American College of Cardiology, vol. 60, no. 4, pp. 346-354, 2012.

[67] W. Whiteley, W. L. Chong, A. Sengupta, and P. Sandercock, "Blood markers for the prognosis of ischemic stroke: a systematic review," Stroke, vol. 40, no. 5, pp. e380-e389, 2009.

[68] M. Matsumoto, T. Nakamachi, J. Watanabe et al., "Pituitary Adenylate Cyclase-Activating Polypeptide (PACAP) is involved in adult mouse hippocampal neurogenesis after stroke," Journal of Molecular Neuroscience, vol. 59, no. 2, pp. 270-279, 2016.

[69] B.-Q. Ma, M. Zhang, and L. Ba, "Plasma pituitary adenylate cyclase-activating polypeptide concentrations and mortality after acute spontaneous basal ganglia hemorrhage," Clinica Chimica Acta, vol. 439, pp. 102-106, 2015.

[70] O. Aze, É. Odjardias, X. Devillard, B. Akplogan, P. Calmels, and P. Giraux, "Structural and physiological muscle changes after post-stroke hemiplegia: a systematic review," Annals of Physical and Rehabilitation Medicine, vol. 59, article e79, 2016.

[71] G. Colaianni, T. Mongelli, S. Colucci, S. Cinti, and M. Grano, "Crosstalk between muscle and bone via the muscle-myokine irisin," Current Osteoporosis Reports, vol. 14, no. 4, pp. 132-137, 2016.

[72] B. K. Pedersen and C. Brandt, "The role of exercise-induced myokines in muscle homeostasis and the defense against chronic diseases," Journal of Biomedicine and Biotechnology, vol. 2010, Article ID 520258, 6 pages, 2010.

[73] D. Di Raimondo, A. Tuttolomondo, G. Musiari, C. Schimmenti, A. D'Angelo, and A. Pinto, "Are the myokines the mediators of physical activity-induced health benefits?" Current Pharmaceutical Design, vol. 22, no. 24, pp. 3622-3647, 2016.

[74] P. Boström, J. Wu, M. P. Jedrychowski et al., "A PGC1- $\alpha$ dependent myokine that drives brown-fat-like development of white fat and thermogenesis," Nature, vol. 481, no. 7382, pp. 463-468, 2012.

[75] Y. Tsuchiya, T. Ijichi, and K. Goto, "Effect of sprint training on resting serum irisin concentration-sprint training once daily vs. twice every other day," Metabolism: Clinical and Experimental, vol. 65, no. 4, pp. 492-495, 2016.

[76] Y. Lu, H. Li, S. Shen et al., "Swimming exercise increases serum irisin level and reduces body fat mass in high-fat-diet fed Wistar rats," Lipids in Health and Disease, vol. 15, no. 1, article no. 93, 2016.

[77] S. H. Lecker, A. Zavin, P. Cao et al., "Expression of the irisin precursor FNDC5 in skeletal muscle correlates with aerobic exercise performance in patients with heart failure," Circulation: Heart Failure, vol. 5, no. 6, pp. 812-818, 2012.

[78] J. Prestes, D. da Cunha Nascimento, R. A. Tibana et al., "Understanding the individual responsiveness to resistance training periodization," Age, vol. 37, no. 3, article no. 55, 2015.

[79] C. D. Wrann, J. P. White, J. Salogiannnis et al., "Exercise induces hippocampal BDNF through a PGC-1 $\alpha /$ FNDC5 pathway," Cell Metabolism, vol. 18, no. 5, pp. 649-659, 2013.

[80] B. Xu, "BDNF (I)rising from exercise," Cell Metabolism, vol. 18, no. 5, pp. 612-614, 2013.

[81] S. Vaynman, Z. Ying, and F. Gómez-Pinilla, "Exercise induces BDNF and synapsin I to specific hippocampal subfields," Journal of Neuroscience Research, vol. 76, no. 3, pp. 356-362, 2004.
[82] G. Leal, D. Comprido, and C. B. Duarte, "BDNF-induced local protein synthesis and synaptic plasticity," Neuropharmacology, vol. 76, pp. 639-656, 2014.

[83] C. Jiang, W. Kong, Y. Wang et al., "Changes in the cellular immune system and circulating inflammatory markers of stroke patients," Oncotarget, vol. 8, no. 2, pp. 3553-3567, 2017.

[84] Z. H. Cheung, W. H. Chin, Y. Chen, Y. P. Ng, and N. Y. Ip, "Cdk5 is involved in BDNF-stimulated dendritic growth in hippocampal neurons," PLoS Biology, vol. 5, no. 4, article e63, 2007.

[85] G. N. Ruegsegger, R. G. Toedebusch, T. E. Childs, K. B. Grigsby, and F. W. Booth, "Loss of Cdk5 function in the nucleus accumbens decreases wheel running and may mediate agerelated declines in voluntary physical activity," The Journal of Physiology, vol. 595, no. 1, pp. 363-384, 2017.

[86] J. Zsuga, G. Tajti, C. Papp, B. Juhasz, and R. Gesztelyi, "FNDC5/irisin, a molecular target for boosting reward-related learning and motivation," Medical Hypotheses, vol. 90, pp. 2328, 2016.

[87] A. Maddahi and L. Edvinsson, "Cerebral ischemia induces microvascular pro-inflammatory cytokine expression via the MEK/ERK pathway," Journal of Neuroinflammation, vol. 7, article 14, 2010.

[88] A. S. Ryan, F. M. Ivey, S. Prior, G. Li, and C. Hafer-Macko, "Skeletal muscle hypertrophy and muscle myostatin reduction after resistive training in stroke survivors," Stroke, vol. 42, no. 2, pp. 416-420, 2011.

[89] D.-S. Han, Y.-M. Chen, S.-Y. Lin et al., "Serum myostatin levels and grip strength in normal subjects and patients on maintenance haemodialysis," Clinical Endocrinology, vol. 75, no. 6, pp. 857-863, 2011.

[90] C.-R. Ju and R.-C. Chen, "Serum myostatin levels and skeletal muscle wasting in chronic obstructive pulmonary disease," Respiratory Medicine, vol. 106, no. 1, pp. 102-108, 2012.

[91] X. Ge, D. Sathiakumar, B. J. G. Lua, H. Kukreti, M. Lee, and C. McFarlane, "Myostatin signals through miR-34a to regulate Fndc5 expression and browning of white adipocytes," International Journal of Obesity, vol. 41, pp. 137-148, 2017.

[92] J. Y. Huh, F. Dincer, E. Mesfum, and C. S. Mantzoros, "Irisin stimulates muscle growth-related genes and regulates adipocyte differentiation and metabolism in humans," International Journal of Obesity, vol. 38, no. 12, pp. 1538-1544, 2014.

[93] M. Foroughi, M. Akhavanzanjani, Z. Maghsoudi, R. Ghiasvand, F. Khorvash, and G. Askari, "Stroke and nutrition: a review of studies," International Journal of Preventive Medicine, vol. 4, pp. S165-S179, 2013.

[94] E. Castillero, H. Akashi, C. Wang et al., "Cardiac myostatin upregulation occurs immediately after myocardial ischemia and is involved in skeletal muscle activation of atrophy," Biochemical and Biophysical Research Communications, vol. 457, no. 1, pp. 106-111, 2015.

[95] B. Feng, W. Wu, H. Wang, J. Wang, D. Huang, and L. Cheng, "Interaction between muscle and bone, and improving the effects of electrical muscle stimulation on amyotrophy and bone loss in a denervation rat model via sciatic neurectomy," Biomedical Reports, vol. 4, no. 5, pp. 589-594, 2016.

[96] M. M. Desgeorges, X. Devillard, J. Toutain et al., "Molecular mechanisms of skeletal muscle atrophy in a mouse model of cerebral ischemia," Stroke, vol. 46, no. 6, pp. 1673-1680, 2015.

[97] G. Lombardi, F. Sanchis-Gomar, S. Perego, V. Sansoni, and G. Banfi, "Implications of exercise-induced adipo-myokines in bone metabolism," Endocrine, vol. 54, no. 2, pp. 284-305, 2016. 
[98] G. Morris, M. Berk, P. Galecki, K. Walder, and M. Maes, "The neuro-immune pathophysiology of central and peripheral fatigue in systemic immune-inflammatory and neuro-immune diseases," Molecular Neurobiology, vol. 53, no. 2, pp. 1195-1219, 2016.

[99] H. Manso, T. Krug, J. Sobral et al., "Variants in the inflammatory IL6 and MPO genes modulate stroke susceptibility through main effects and gene-gene interactions," Journal of Cerebral Blood Flow and Metabolism, vol. 31, no. 8, pp. 1751-1759, 2011.

[100] S. S. Welc, T. L. Clanton, S. M. Dineen, and L. R. Leon, "Heat stroke activates a stress-induced cytokine response in skeletal muscle," Journal of Applied Physiology, vol. 115, no. 8, pp. 11261137, 2013.

[101] S. Gielen, V. Adams, S. Möbius-Winkler et al., "Anti-inflammatory effects of exercise training in the skeletal muscle of patients with chronic heart failure," Journal of the American College of Cardiology, vol. 42, no. 5, pp. 861-868, 2003.

[102] D. E. Forman, K. M. Daniels, L. P. Cahalin et al., "Analysis of skeletal muscle gene expression patterns and the impact of functional capacity in patients with systolic heart failure," Journal of Cardiac Failure, vol. 20, no. 6, pp. 422-430, 2014.

[103] C. Jiang, W. Kong, Y. Wang et al., "Changes in the cellular immune system and circulating inflammatory markers of stroke patients," Oncotarget, 2016.

[104] Z. Su, L. Hu, J. Cheng et al., "Acupuncture plus low-frequency electrical stimulation (Acu-LFES) attenuates denervationinduced muscle atrophy," Journal of Applied Physiology, vol. 120, no. 4, pp. 426-436, 2016.

[105] Z. Su, A. Robinson, L. Hu et al., "Acupuncture plus lowfrequency electrical stimulation (Acu-LFES) attenuates diabetic myopathy by enhancing muscle regeneration," PLOS ONE, vol. 10, no. 7, Article ID e0134511, 2015.

[106] C. Kang and L. Li Ji, "Role of PGC- $1 \alpha$ signaling in skeletal muscle health and disease," Annals of the New York Academy of Sciences, vol. 1271, no. 1, pp. 110-117, 2012.

[107] A. Vainshtein and D. A. Hood, "The regulation of autophagy during exercise in skeletal muscle," Journal of Applied Physiology, vol. 120, no. 6, pp. 664-673, 2016.

[108] P. A. Grimaldi, "Roles of PPAR $\delta$ in the control of muscle development and metabolism," Biochemical Society Transactions, vol. 31, no. 6, pp. 1130-1132, 2003.

[109] W. J. Smiles, E. B. Parr, V. G. Coffey, O. Lacham-Kaplan, J. A. Hawley, and D. M. Camera, "Protein coingestion with alcohol following strenuous exercise attenuates alcohol-induced intramyocellular apoptosis and inhibition of autophagy," American Journal of Physiology-Endocrinology And Metabolism, vol. 311, no. 5, pp. E836-E849, 2016.

[110] A. Botta, I. Laher, J. Beam et al., "Short term exercise induces PGC- $1 \alpha$, ameliorates inflammation and increases mitochondrial membrane proteins but fails to increase respiratory enzymes in aging diabetic hearts," PLoS ONE, vol. 8, no. 8, Article ID e70248, 2013.

[111] M. J. Abbott, J. E. Krolopp, S. M. Thornton, and A. Kawata, "PPAR $\delta$ is required For IL-15-induced mitochondrial activity in C2C12 skeletal muscle cells," Medicine \& Science in Sports \& Exercise, vol. 48, no. 5, supplement 1, p. 544, 2016.

[112] M. Molanouri Shamsi, Z. H. Hassan, R. Gharakhanlou et al., "Expression of interleukin-15 and inflammatory cytokines in skeletal muscles of STZ-induced diabetic rats: effect of resistance exercise training," Endocrine, vol. 46, no. 1, pp. 6069, 2014.
[113] H. C. Kim, H.-Y. Cho, and Y.-S. Hah, "Role of IL-15 in sepsisinduced skeletal muscle atrophy and proteolysis," Tuberculosis and Respiratory Diseases, vol. 73, no. 6, pp. 312-319, 2012.

[114] W. Xie, L. Fang, S. Gan, and H. Xuan, "Interleukin-19 alleviates brain injury by anti-inflammatory effects in a mice model of focal cerebral ischemia," Brain Research, vol. 1650, pp. 172-177, 2016.

[115] P. Korhonen, K. M. Kanninen, Š. Lehtonen et al., "Immunomodulation by interleukin-33 is protective in stroke through modulation of inflammation," Brain, Behavior, and Immunity, vol. 49, pp. 322-336, 2015.

[116] M. J. Drummond, K. L. Timmerman, M. M. Markofski et al., "Short-term bed rest increases TLR4 and IL-6 expression in skeletal muscle of older adults," American Journal of Physiology-Regulatory Integrative and Comparative Physiology, vol. 305, no. 3, pp. R216-R223, 2013.

[117] S. E. Conway, M. Roy-O’Reilly, B. Friedler, I. Staff, G. Fortunato, and L. D. McCullough, "Sex differences and the role of IL-10 in ischemic stroke recovery," Biology of Sex Differences, vol. 6, article 17, 2015.

[118] W. He, H. Song, L. Ding, C. Li, L. Dai, and S. Gao, "Association between IL-10 gene polymorphisms and the risk of ischemic stroke in a Chinese population," International Journal of Clinical and Experimental Pathology, vol. 8, no. 10, pp. 13489-13494, 2015.

[119] S. P. M. Janssen, G. Gayan-Ramirez, A. Van Den Bergh et al., "Interleukin-6 causes myocardial failure and skeletal muscle atrophy in rats," Circulation, vol. 111, no. 8, pp. 996-1005, 2005.

[120] L. Pelosi, M. G. Berardinelli, L. De Pasquale et al., "Functional and morphological improvement of dystrophic muscle by interleukin 6 receptor blockade," EBioMedicine, vol. 2, no. 4, pp. 285-293, 2015.

[121] M. A. Alam, V. P. Subramanyam Rallabandi, and P. K. Roy, "Systems biology of immunomodulation for post-stroke neuroplasticity: multimodal implications of pharmacotherapy and neurorehabilitation," Frontiers in Neurology, vol. 7, article 94, 2016.

[122] Y. Lin, J. C. Zhang, C. Y. Yao et al., "Critical role of astrocytic interleukin-17 A in post-stroke survival and neuronal differentiation of neural precursor cells in adult mice," Cell Death and Disease, vol. 7, no. 6, Article ID e2273, 2016.

[123] K. Kanda, K. Sugama, J. Sakuma, Y. Kawakami, and K. Suzuki, "Evaluation of serum leaking enzymes and investigation into new biomarkers for exerciseinduced muscle damage," Exercise Immunology Review, vol. 20, pp. 39-54, 2014.

[124] J. M. Peake, P. D. Gatta, K. Suzuki, and D. C. Nieman, "Cytokine expression and secretion by skeletal muscle cells: regulatory mechanisms and exercise effects," Exercise Immunology Review, vol. 21, pp. 8-25, 2015.

[125] R. H. Wu, P. Wang, L. Yang, Y. Li, Y. Liu, and M. Liu, "A potential indicator of denervated muscle atrophy: the ratio of myostatin to follistatin in peripheral blood," Genetics and Molecular Research, vol. 10, no. 4, pp. 3914-3923, 2011.

[126] A. D. Anastasilakis, S. A. Polyzos, E. C. Skouvaklidou et al., "Circulating follistatin displays a day-night rhythm and is associated with muscle mass and circulating leptin levels in healthy, young humans," Metabolism, vol. 65, no. 10, pp. 14591465, 2016.

[127] S. Raschke, K. Eckardt, K. Bjørklund Holven, J. Jensen, and J. Eckel, "Identification and validation of novel contractionregulated myokines released from primary human skeletal muscle cells," PLoS ONE, vol. 8, no. 4, Article ID e62008, 2013. 
[128] M. Catoire, M. Mensink, E. Kalkhoven, P. Schrauwen, and S. Kersten, "Identification of human exercise-induced myokines using secretome analysis," Physiological Genomics, vol. 46, no. 7, pp. 256-267, 2014.

[129] N. Ouchi, Y. Oshima, K. Ohashi et al., "Follistatin-like 1, a secreted muscle protein, promotes endothelial cell function and revascularization in ischemic tissue through a nitricoxide synthase-dependent mechanism," Journal of Biological Chemistry, vol. 283, no. 47, pp. 32802-32811, 2008.

[130] Y. Chaly, B. Hostager, S. Smith, and R. Hirsch, "Follistatinlike protein 1 and its role in inflammation and inflammatory diseases," Immunologic Research, vol. 59, no. 1-3, pp. 266-272, 2014.

[131] S. Raschke and J. Eckel, "Adipo-myokines: two sides of the same coin-mediators of inflammation and mediators of exercise," Mediators of Inflammation, vol. 2013, Article ID 320724, 16 pages, 2013.

[132] X. Liang, Q. Hu, B. Li et al., "Follistatin-like 1 attenuates apoptosis via disco-interacting protein 2 homolog A/Akt pathway after middle cerebral artery occlusion in rats," Stroke, vol. 45, no. 10, pp. 3048-3054, 2014.

[133] N. Ouchi, Y. Asaumi, K. Ohashi et al., "DIP2A functions as a FSTL1 receptor," Journal of Biological Chemistry, vol. 285, no. 10, pp. 7127-7134, 2010.

[134] Y. Xi, D.-W. Gong, and Z. Tian, "FSTL1 as a potential mediator of exercise-induced cardioprotection in post-myocardial infarction rats," Scientific Reports, vol. 6, Article ID 32424, 2016.

[135] M. Zille, A. Riabinska, M. Y. Terzi et al., "Influence of pigment epithelium-derived factor on outcome after striatal cerebral ischemia in the mouse," PLoS ONE, vol. 9, no. 12, Article ID el14595, 2014.

[136] A. Takanohashi, T. Yabe, and J. P. Schwartz, "Pigment epithelium-derived factor induces the production of chemokines by rat microglia," GLIA, vol. 51, no. 4, pp. 266-278, 2005.

[137] V. Darsalia, M. Larsson, D. Nathanson, T. Klein, T. Nyström, and C. Patrone, "Glucagon-like receptor 1 agonists and DPP4 inhibitors: potential therapies for the treatment of stroke," Journal of Cerebral Blood Flow and Metabolism, vol. 35, no. 5, pp. 718-723, 2015.

[138] K. Tziomalos, S. D. Bouziana, M. Spanou et al., "Prior treatment with dipeptidyl peptidase 4 inhibitors is associated with better functional outcome and lower in-hospital mortality in patients with type 2 diabetes mellitus admitted with acute ischaemic stroke," Diabetes and Vascular Disease Research, vol. 12, no. 6, pp. 463-466, 2015.

[139] M. DeNicola, J. Du, Z. Wang et al., "Stimulation of glucagonlike peptide-1 receptor through exendin-4 preserves myocardial performance and prevents cardiac remodeling in infarcted myocardium," American Journal of Physiology-Endocrinology and Metabolism, vol. 307, no. 8, pp. E630-E643, 2014.

[140] S. Takada, Y. Masaki, S. Kinugawa et al., "Dipeptidyl peptidase4 inhibitor improved exercise capacity and mitochondrial biogenesis in mice with heart failure via activation of glucagonlike peptide-1 receptor signalling," Cardiovascular Research, vol. 111, no. 4, pp. 338-347, 2016.

[141] T. Karagiannis, P. Paschos, K. Paletas, D. R. Matthews, and A. Tsapas, "Dipeptidyl peptidase- 4 inhibitors for treatment of type 2 diabetes mellitus in the clinical setting: systematic review and meta-analysis," BMJ, vol. 344, no. 7850, Article ID e1369, 2012.

[142] H. Lee, H. Chang, S. Lee et al., "Role of $\mathrm{IGF1R}^{+}$MSCs in modulating neuroplasticity via CXCR4 cross-interaction," Scientific Reports, vol. 6, Article ID 32595, 2016.
[143] H. K. Haider, S. Jiang, N. M. Idris, and M. Ashraf, "IGF-1overexpressing mesenchymal stem cells accelerate bone marrow stem cell mobilization via paracrine activation of SDF$1 \alpha /$ CXCR4 signaling to promote myocardial repair," Circulation Research, vol. 103, no. 11, pp. 1300-1308, 2008.

[144] A. Arnarson, O. G. Geirsdottir, A. Ramel, P. V. Jonsson, and I. Thorsdottir, "Insulin-like growth factor-1 and resistance exercise in community dwelling old adults," Journal of Nutrition, Health and Aging, vol. 19, no. 8, pp. 856-860, 2015.

[145] M. Ploughman, M. W. Austin, L. Glynn, and D. Corbett, "The effects of poststroke aerobic exercise on neuroplasticity: a systematic review of animal and clinical studies," Translational Stroke Research, vol. 6, no. 1, pp. 13-28, 2015.

[146] C. S. Mang, K. L. Campbell, C. J. D. Ross, and L. A. Boyd, "Promoting neuroplasticity for motor rehabilitation after stroke: considering the effects of aerobic exercise and genetic variation on brain-derived neurotrophic factor," Physical Therapy, vol. 93, no. 12, pp. 1707-1716, 2013.

[147] J. Li, Y. Tang, Y. Wang et al., "Neurovascular recovery via cotransplanted neural and vascular progenitors leads to improved functional restoration after ischemic stroke in rats," Stem Cell Reports, vol. 3, no. 1, pp. 101-114, 2014.

[148] X. Cui, M. Chopp, A. Zacharek et al., "D-4F decreases white matter damage after stroke in mice," Stroke, vol. 47, no. 1, pp. 214-220, 2016.

[149] H. Okazaki, H. Beppu, K. Mizutani, S. Okamoto, and S. Sonoda, "Changes in serum growth factors in stroke rehabilitation patients and their relation to hemiparesis improvement," Journal of Stroke and Cerebrovascular Diseases, vol. 23, no. 6, pp. 1703-1708, 2014.

[150] A. E. Mattlage, M. A. Rippee, J. Sandt, and S. A. Billinger, "Decrease in insulin-like growth factor-1 and insulin-like growth factor-1 ratio in the first week of stroke is related to positive outcomes," Journal of Stroke and Cerebrovascular Diseases, vol. 25, no. 7, pp. 1800-1806, 2016.

[151] S. P. Johnsen, H. H. Hundborg, H. T. Sørensen et al., "Insulinlike growth factor (IGF) I, -II, and IGF binding protein-3 and risk of ischemic stroke," Journal of Clinical Endocrinology and Metabolism, vol. 90, no. 11, pp. 5937-5941, 2005.

[152] R. C. Kaplan, A. P. McGinn, M. N. Pollak et al., "Association of total insulin-like growth factor-I, insulin-like growth factor binding protein-1 (IGFBP-1), and IGFBP-3 levels with incident coronary events and ischemic stroke," Journal of Clinical Endocrinology and Metabolism, vol. 92, no. 4, pp. 1319-1325, 2007.

[153] Y. Xiao, L. Liu, A. Xu et al., "Serum fibroblast growth factor 21 levels are related to subclinical atherosclerosis in patients with type 2 diabetes," Cardiovascular Diabetology, vol. 14, article 72, 2015.

[154] E. Lovadi, M. Csereklyei, H. Merkli et al., "Elevated FGF 21 in myotonic dystrophy type 1 and mitochondrial diseases," Muscle \& Nerve, 2016.

[155] X. Wang, H. Xiao, L. Liu, D. Cheng, X. Li, and L. Si, "FGF21 represses cerebrovascular aging via improving mitochondrial biogenesis and inhibiting p53 signaling pathway in an AMPKdependent manner," Experimental Cell Research, vol. 346, no. 2, pp. 147-156, 2016.

[156] P. Lee, J. Linderman, S. Smith et al., "Fibroblast growth factor 21 (FGF21) and bone: is there a relationship in humans?" Osteoporosis International, vol. 24, no. 12, pp. 3053-3057, 2013.

[157] X. Li, S. Stanislaus, F. Asuncion et al., "FGF21 is not a major mediator for bone homeostasis or metabolic actions of PPAR $\alpha$ 
and PPAR $\gamma$ agonists," Journal of Bone and Mineral Research, 2016.

[158] C. Loyd, I. J. Magrisso, M. Haas et al., "Fibroblast growth factor 21 is required for beneficial effects of exercise during chronic high-fat feeding," Journal of Applied Physiology, vol. 121, no. 3, pp. $687-698,2016$.

[159] X. Xu and Y. Jiang, "The yin and yang of innate immunity in stroke," BioMed Research International, vol. 2014, Article ID 807978, 8 pages, 2014.

[160] D. Petrovic-Djergovic, S. N. Goonewardena, and D. J. Pinsky, "Inflammatory disequilibrium in stroke," Circulation Research, vol. 119, no. 1, pp. 142-158, 2016.

[161] J. H. Tapia-Pérez, D. Karagianis, R. Zilke, V. Koufuglou, I. Bondar, and T. Schneider, "Assessment of systemic cellular inflammatory response after spontaneous intracerebral hemorrhage," Clinical Neurology and Neurosurgery, vol. 150, pp. 72-79, 2016.

[162] H.-Y. Fang, W.-J. Ko, and C.-Y. Lin, "Plasma interleukin 11 levels correlate with outcome of spontaneous intracerebral hemorrhage," Surgical Neurology, vol. 64, no. 6, pp. 511-517, 2005.

[163] A. Tuttolomondo, D. Di Raimondo, R. di Sciacca, A. Pinto, and G. Licata, "Inflammatory cytokines in acute ischemic stroke," Current Pharmaceutical Design, vol. 14, no. 33, pp. 3574-3589, 2008.

[164] A. Tuttolomondo, D. Di Raimondo, R. Pecoraro, V. Arnao, A. Pinto, and G. Licata, "Inflammation in ischemic stroke subtypes," Current Pharmaceutical Design, vol. 18, no. 28, pp. 4289-4310, 2012.

[165] X. Chen, Y. Wang, M. Fu, H. Lei, Q. Cheng, and X. Zhang, "Plasma immunoproteasome predicts early hemorrhagic transformation in acute ischemic stroke patients," Journal of Stroke and Cerebrovascular Diseases, vol. 26, no. 1, pp. 49-56, 2017.

[166] A. Tuttolomondo, R. Pecoraro, A. Casuccio et al., "Peripheral frequency of CD4+ CD28-cells in acute ischemic stroke relationship with stroke subtype and severity markers," Medicine (Baltimore), vol. 94, no. 20, article no. e813, 2015.

[167] Z. G. Nadareishvili, H. Li, V. Wright et al., "Elevated proinflammatory CD4+CD28- lymphocytes and stroke recurrence and death," Neurology, vol. 63, no. 8, pp. 1446-1451, 2004.

[168] S. Chen, H. Wu, D. Klebe, Y. Hong, J. Zhang, and J. Tang, "Regulatory $\mathrm{T}$ cell in stroke: a new paradigm for immune regulation," Clinical and Developmental Immunology, vol. 2013, Article ID 689827, 9 pages, 2013.

[169] P. Li, L. Mao, X. Liu et al., "Essential role of program death 1ligand 1 in regulatory T-cell-afforded protection against bloodbrain barrier damage after stroke," Stroke, vol. 45, no. 3, pp. 857864, 2014.

[170] Y. Xia, W. Cai, A. W. Thomson, and X. Hu, "Regulatory T cell therapy for ischemic stroke: how far from clinical translation?" Translational Stroke Research, vol. 7, no. 5, pp. 415-419, 2016.

[171] S. Neumann, N. J. Shields, T. Balle, M. Chebib, and A. N. Clarkson, "Innate immunity and inflammation post-stroke: an $\alpha 7$-nicotinic agonist perspective," International Journal of Molecular Sciences, vol. 16, no. 12, pp. 29029-29046, 2015.

[172] Z. Wang, L. Xue, T. Wang, X. Wang, and Z. Su, "Infiltration of invariant natural killer $\mathrm{T}$ cells occur and accelerate brain infarction in permanent ischemic stroke in mice," Neuroscience Letters, vol. 633, pp. 62-68, 2016.
[173] T. Homma, S. Kinugawa, M. Takahashi et al., "Activation of invariant natural killer T cells by $\alpha$-galactosylceramide ameliorates myocardial ischemia/reperfusion injury in mice," Journal of Molecular and Cellular Cardiology, vol. 62, pp. 179-188, 2013.

[174] S. De Raedt, A. De Vos, A. Van Binst et al., "High natural killer cell number might identify stroke patients at risk of developing infections," Neurology-Neuroimmunology Neuroinflammation, vol. 2, no. 2, article no. e71, 2015.

[175] Y. Zhang, Z. Gao, D. Wang et al., "Accumulation of natural killer cells in ischemic brain tissues and the chemotactic effect of IP10," Journal of Neuroinflammation, vol. 11, article no. 79, 2014.

[176] L. Gu, X. Xiong, D. Wei, X. Gao, S. Krams, and H. Zhao, "T cells contribute to stroke-induced lymphopenia in rats," PLOS ONE, vol. 8, no. 3, Article ID e59602, 2013.

[177] D. Gill and R. Veltkamp, "Dynamics of T cell responses after stroke," Current Opinion in Pharmacology, vol. 26, pp. 26-32, 2016.

[178] J. Klehmet, S. Hoffmann, G. Walter, C. Meisel, and A. Meisel, "Stroke induces specific alteration of $\mathrm{T}$ memory compartment controlling auto-reactive CNS antigen-specific T cell responses," Journal of the Neurological Sciences, vol. 368, pp. 7783, 2016.

[179] Y. Hu, Y. Zheng, Y. Wu, B. Ni, and S. Shi, "Imbalance between IL-17A-producing cells and regulatory T cells during ischemic stroke," Mediators of Inflammation, vol. 2014, Article ID 813045, 8 pages, 2014.

[180] X. Wang, H. Li, and S. Ding, "Pre-B-cell colony-enhancing factor protects against apoptotic neuronal death and mitochondrial damage in ischemia," Scientific Reports, vol. 6, article 32416, 2016.

[181] U. M. Selvaraj, K. Poinsatte, V. Torres, S. B. Ortega, and A. M. Stowe, "Heterogeneity of B cell functions in stroke-related risk, prevention, injury, and repair," Neurotherapeutics, vol. 13, no. 4, pp. 729-747, 2016.

[182] X. Ren, K. Akiyoshi, S. Dziennis et al., "Regulatory B cells limit CNS inflammation and neurologic deficits in murine experimental stroke," Journal of Neuroscience, vol. 31, no. 23, pp. 8556-8563, 2011.

[183] A. Liesz and C. Kleinschnitz, "Regulatory T cells in post-stroke immune homeostasis," Translational Stroke Research, vol. 7, no. 4, pp. 313-321, 2016.

[184] L.-B. Guo, S. Liu, F. Zhang, G.-S. Mao, L.-Z. Sun, and Y. Liu, "The role of eosinophils in stroke: A Pilot Study" European Review for Medical and Pharmacological Sciences, vol. 19, no. 19, pp. 3643-3648, 2015.

[185] I. Maestrini, D. Strbian, S. Gautier et al., "Higher neutrophil counts before thrombolysis for cerebral ischemia predict worse outcomes," Neurology, vol. 85, no. 16, pp. 1408-1416, 2015.

[186] L. Roever and S. R. Levine, "Cerebral hemorrhage following thrombolytic therapy for stroke: are neutrophils really neutral?" Neurology, vol. 85, no. 16, pp. 1360-1361, 2015.

[187] E. Thonnard-Neumann, "Monocytes and basophilic granulocytes in the cranial circulation of patients with organic brain disorders," Stroke, vol. 3, no. 3, pp. 286-299, 1972.

[188] P. J. Lindsberg, D. Strbian, and M.-L. Karjalainen-Lindsberg, "Mast cells as early responders in the regulation of acute bloodbrain barrier changes after cerebral ischemia and hemorrhage," Journal of Cerebral Blood Flow and Metabolism, vol. 30, no. 4, pp. 689-702, 2010.

[189] M. S. Woo, J. Yang, C. Beltran, and S. Cho, "Cell surface CD36 protein in monocyte/macrophage contributes to phagocytosis 
during the resolution phase of ischemic stroke in mice," The Journal of Biological Chemistry, vol. 291, no. 45, pp. 2365423661, 2016.

[190] S. Wattananit, D. Tornero, N. Graubardt et al., "Monocytederived macrophages contribute to spontaneous long-term functional recovery after stroke in mice," Journal of Neuroscience, vol. 36, no. 15, pp. 4182-4195, 2016.

[191] A. ElAli and N. J. LeBlanc, "The role of monocytes in ischemic stroke pathobiology: new avenues to explore," Frontiers in Aging Neuroscience, vol. 8, article no. 29, 2016.

[192] J. C. Felger, T. Abe, U. W. Kaunzner et al., "Brain dendritic cells in ischemic stroke: time course, activation state, and origin," Brain, Behavior, and Immunity, vol. 24, no. 5, pp. 724-737, 2010.

[193] X. Urra, F. Miró, A. Chamorro, and A. M. Planas, "Antigenspecific immune reactions to ischemic stroke," Frontiers in Cellular Neuroscience, vol. 8, article 278, 2014.

[194] A. Hug, A. Liesz, B. Muerle et al., "Reduced efficacy of circulating costimulatory cells after focal cerebral ischemia," Stroke, vol. 42, no. 12, pp. 3580-3586, 2011.

[195] A. Yilmaz, T. Fuchs, B. Dietel et al., "Transient decrease in circulating dendritic cell precursors after acute stroke: potential recruitment into the brain," Clinical Science, vol. 118, no. 2, pp. 147-157, 2010.

[196] K. Duris and J. Lipkova, "The role of microRNA in ischemic and hemorrhagic stroke," Current Drug Delivery, vol. 14, no. 8, 2017.

[197] J. Kim, G. H. Choi, K. H. Ko et al., "Association of the single nucleotide polymorphisms in microRNAs 130b, 200b, and 495 with ischemic stroke susceptibility and post-stroke mortality," PLoS ONE, vol. 11, no. 9, Article ID e0162519, 2016.

[198] K. Toyama, J. Spin, and P. Tsao, "Role of microRNAs on blood brain barrier dysfunction in vascular cognitive impairment," Current Drug Delivery, vol. 13, pp. 1-14, 2016.

[199] A. Karthikeyan, R. Patnala, S. Jadhav, L. Eng-Ang, and S. Dheen, "MicroRNAs: key players in microglia and astrocyte mediated inflammation in CNS pathologies," Current Medicinal Chemistry, vol. 23, no. 30, pp. 3528-3546, 2016.

[200] M. Vijayan and P. H. Reddy, "Peripheral biomarkers of stroke: focus on circulatory microRNAs," Biochimica et Biophysica Acta, vol. 1862, no. 10, pp. 1984-1993, 2016.

[201] R. Zhang, Y. Qin, G. Zhu, Y. Li, and J. Xue, "Low serum miR320 b expression as a novel indicator of carotid atherosclerosis," Journal of Clinical Neuroscience, vol. 33, pp. 252-258, 2016.

[202] X. Zhou, S. Su, S. Li et al., "MicroRNA-146a down-regulation correlates with neuroprotection and targets pro-apoptotic genes in cerebral ischemic injury in vitro," Brain Research, vol. 1648, pp. 136-143, 2016.

[203] P. Wang, J. Liang, Y. Li et al., "Down-regulation of miRNA-30a alleviates cerebral ischemic injury through enhancing Beclin 1mediated autophagy," Neurochemical Research, vol. 39, no. 7, pp. 1279-1291, 2014.

[204] Z. Peng, J. Li, Y. Li et al., "Downregulation of miR-181b in mouse brain following ischemic stroke induces neuroprotection against ischemic injury through targeting heat shock protein A5 and ubiquitin carboxyl-terminal hydrolase isozyme L1," Journal of Neuroscience Research, vol. 91, no. 10, pp. 1349-1362, 2013.

[205] P. Wang, N. Zhang, J. Liang, J. Li, S. Han, and J. Li, "MicroRNA-30a regulates ischemia-induced cell death by targeting heat shock protein HSPA5 in primary cultured cortical neurons and mouse brain after stroke," Journal of Neuroscience Research, vol. 93, no. 11, pp. 1756-1768, 2015.
[206] D. A. Duricki, T. H. Hutson, C. Kathe et al., "Delayed intramuscular human neurotrophin-3 improves recovery in adult and elderly rats after stroke," Brain, vol. 139, no. 1, pp. 259-275, 2016.

[207] L. Lorente, M. M. Martín, T. Almeida et al., "Serum levels of substance $\mathrm{P}$ and mortality in patients with a severe acute ischemic stroke," International Journal of Molecular Sciences, vol. 17, no. 6, article no. 991, 2016.

[208] Q. Li, Y. Lin, W. Huang et al., "Serum IL-33 is a novel diagnostic and prognostic biomarker in acute ischemic stroke," Aging and Disease, vol. 7, no. 5, pp. 614-622, 2016.

[209] S. M. Lloyd-Burton, E. M. York, M. A. Anwar, A. J. Vincent, and A. J. Roskams, "SPARC regulates microgliosis and functional recovery following cortical ischemia," Journal of Neuroscience, vol. 33, no. 10, pp. 4468-4481, 2013.

[210] L. Minshu, L. Zhiguo, W. Kristofer, J. Weina, S. Fu-Dong, and L. Qiang, "Abstract 144: astrocyte-derived interleukin15 accelarates Ischemic Brain Injury Int Stroke Conference," Stroke, vol. 47, article A144, 2016. 

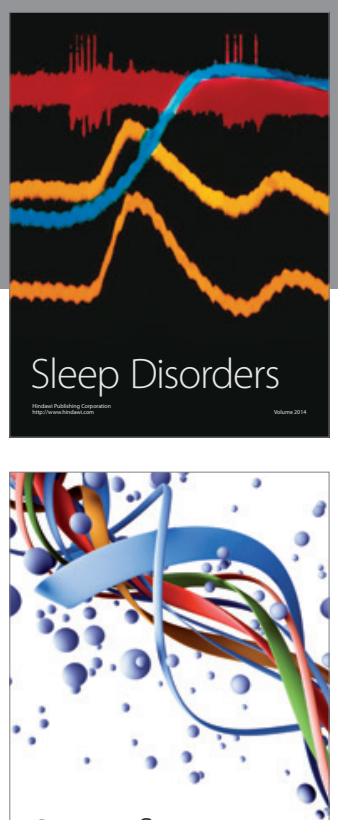

Scientifica
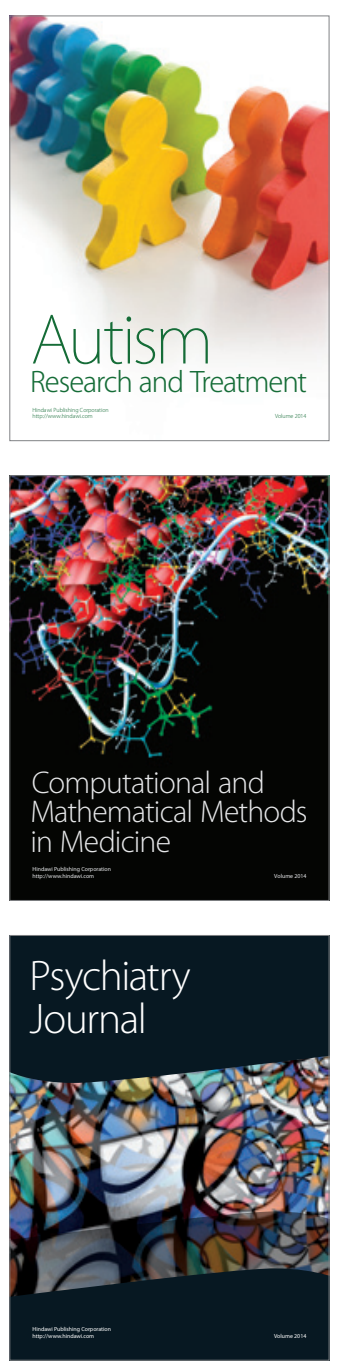
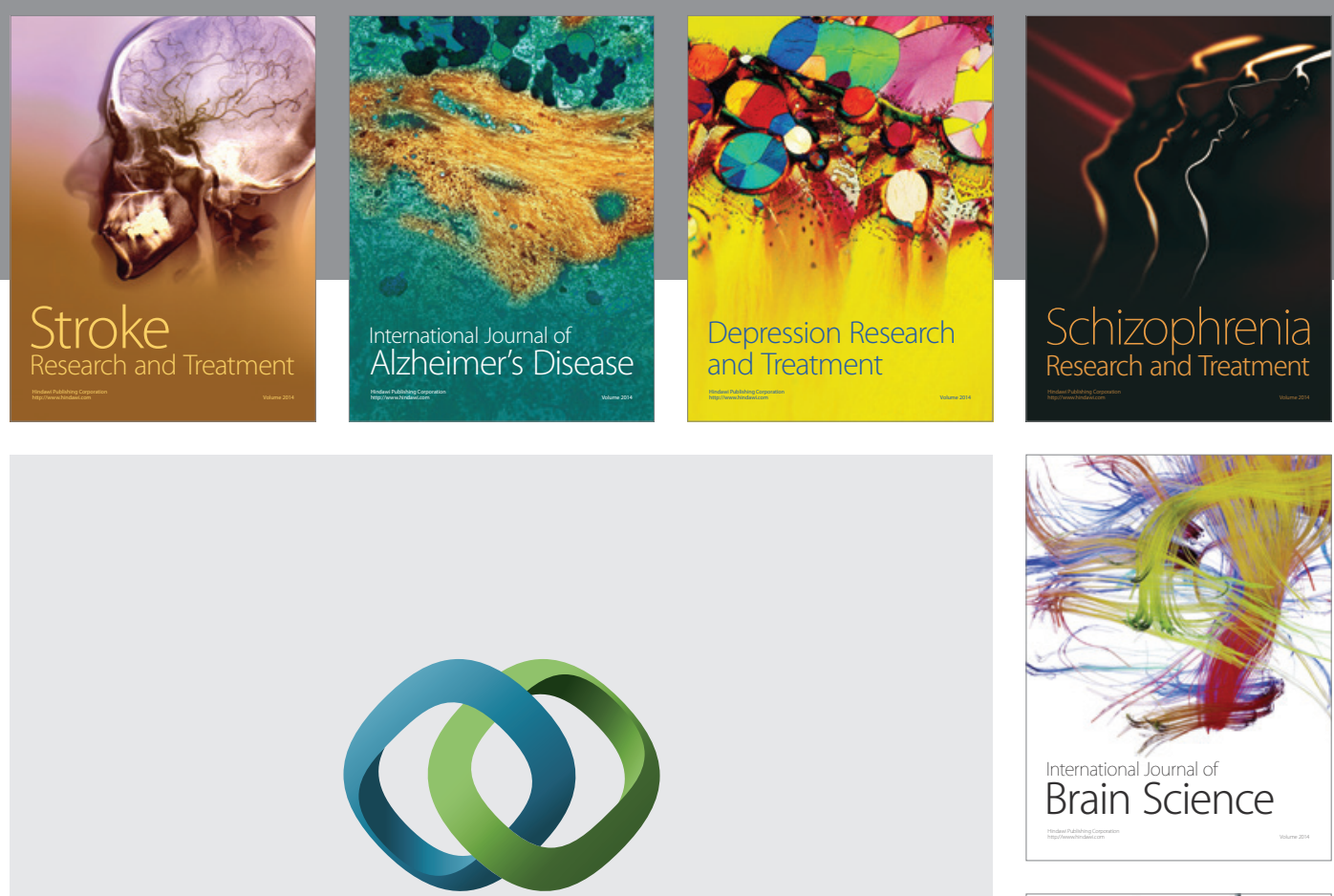

\section{Hindawi}

Submit your manuscripts at

https://www.hindawi.com
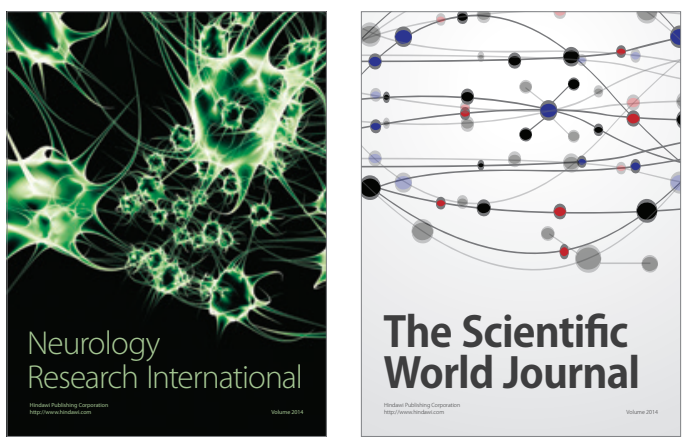

The Scientific World Journal

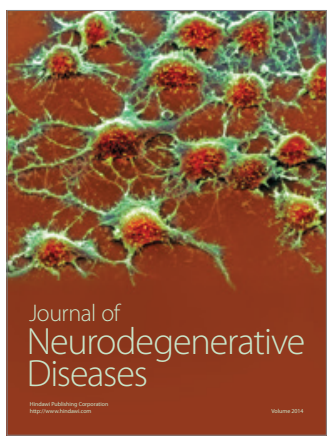

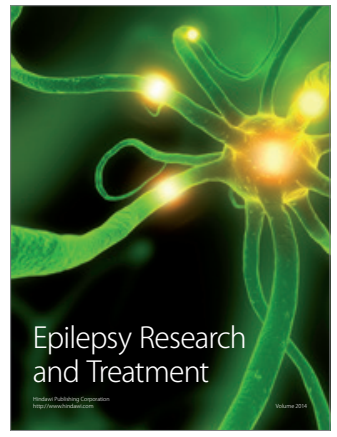

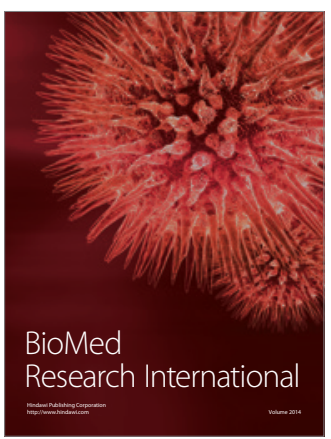

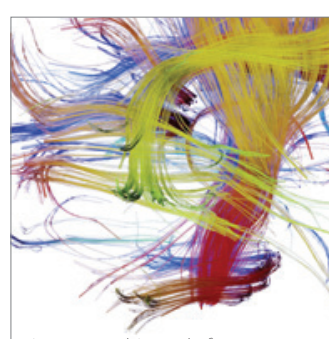

Brain Science

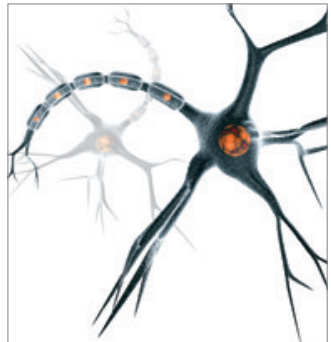

Neural Plasticity
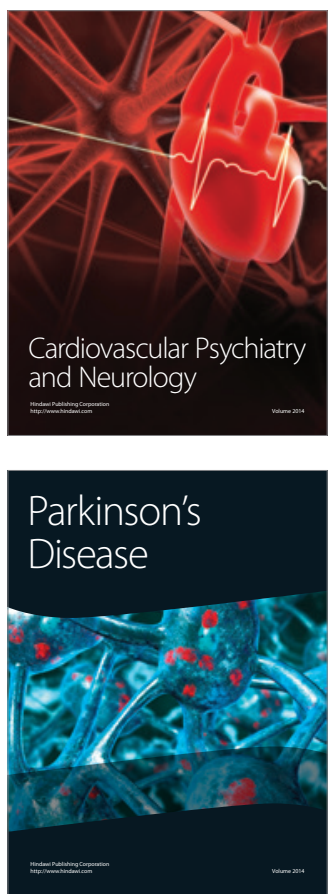